\title{
The Dynamic Efficiency Costs of Common-Pool Resource Exploitation
}

\author{
By Ling Huang And Martin D. SMith *
}

\begin{abstract}
We conduct the first empirical investigation of common-pool resource users' dynamic and strategic behavior at the micro level using realworld data. Fishermen's strategies in a fully dynamic game account for latent resource dynamics and other players' actions, revealing the profit structure of the fishery. We compare the fishermen's actual and socially optimal exploitation paths under a time-specific vessel allocation policy and find a sizable dynamic externality. Individual fishermen respond to other users by exerting effort above the optimal level early in the season. Congestion is costly instantaneously but is beneficial in the long run because it partially offsets dynamic inefficiencies.

JEL: C61 C73 Q22

Keywords: Dynamic efficiency costs, Open access, Dynamic games, Latent stock
\end{abstract}

Common-pool resource exploitation—-known popularly as the "Tragedy of the Commons" (Hardin 1968) - has attracted attention from numerous scholars. Despite considerable intellectual effort, ${ }^{1}$ little is known empirically about the pathways through which the commons affects individual behavior and leads to inefficiency. Open access to resources, or at least minimal levels of excludability, can generate multiple inefficiencies.

* Huang: Assistant Professor, Department of Economics, 365 Fairfield way, University of Connecticut, Storrs, CT 06269. ling.huang@uconn.edu; Smith: Dan and Bunny Gabel Associate Professor, Nicholas School of the Environment and Department of Economics, Duke University, Box 90328, Durham, NC 27708. marsmith@duke.edu. The authors thank the North Carolina Division of Marine Fisheries, in particular, A. Bianchi, S. McKenna, and K. West for access to shrimp fishery and monitoring data. Financial support for this project was provided in part by the National Oceanic and Atmospheric administration (NOAA) Center for Sponsored Coastal Ocean Research under award \# NA05NOS4781197 to J.K. Craig, L.B. Crowder, M.D. Smith (Duke University). The views expressed herein are those of the authors and do not necessarily reflect the view of NOAA or any of its sub-agencies. The authors are also deeply grateful to Christopher Timmins, Han Hong, Randall A. Kramer, V. Joseph Hotz, Victor Aguirregabiria, Haifeng Huang, Kerry Smith, Song Yao, Jason R. Blevins, Sathya Gopalakrishnan, Zachary Brown, Junjie Zhang, David Layton, Dale Squires, Jim Wilen, Frank Asche, two anonymous reviewers, the editor, and seminar and conference participants at the 2011 AERE Summer Conference in Seattle, WA, the 2009 Western Economic Association meetings in Vancouver, B.C., Camp Resources 2007 in Wilmington, NC, Duke University, Resources for the Future, UC Davis, UCSD, NOAA Southwest Fisheries Science Center, University of Connecticut, and University of Calgary. The authors declare that they have no relevant or material financial interests that relate to the research described in this paper.

${ }^{1}$ Common-pool resources are rival in consumption but exhibit some degree of non-excludability with the limiting cases being private goods (perfect excludability) and open access goods (perfect non-excludability). In his seminal article, H. Scott Gordon (1954) observed that open access in a fishery leads to dissipation of economic rents and a resource stock that is below its economically optimal level. Subsequent work has applied common-pool resource theory to a wide range of natural resource uses including oil extraction (Libecap and Wiggins 1984), ground water withdrawals (Provencher and Burt 1993), hunting and large animal extinctions (Smith 1975), deforestation (Mendelsohn 1994), fuelwood collection (Linde-Rahr 2003), and even depletion of the environmental basis for a whole society (Brander and Taylor 1998). In their classic reference on exhaustible resource theory, Dasgupta and Heal (Dasgupta and Heal 1979) observe,"A remarkable feature of the problem of common property resource is the variety of examples that one can rather readily construct in exemplifying it." (p. 78). 
First generation theoretical work focused on the stock externality; the actions of one agent affect the stock of the resource, which in turn affects the well-being of another agent through decreased resource availability or increased costs (Gordon 1954; Smith 1969). ${ }^{2}$ Resource exploitation is sometimes too high and sometimes too low due to the stock externality, so open access can also lead to inefficient timing of exploitation (Smith 1969). ${ }^{3}$ A separate congestion externality is static in nature; resource users can increase each other's costs contemporaneously through crowding on harvest grounds (Smith 1969).

The second generation of common-pool resource theory adopted a game-theoretic approach, but direct empirical testing has been elusive. Game-theoretic models posit that resource users directly affect the actions of other resource users, giving rise to the "tragedy of the commons." Users are typically modeled as players in an N-person game (Baland and Platteau 2003; Dawes 1973; Sethi and Somanathan 1996). ${ }^{4}$ While an Nperson game matches the story of the commons nicely, empirical work has focused on the aggregate level (Bjørndal and Conrad 1987; Wilen 1976). Little progress has been made in empirically estimating the strategic interactions of resource users, and we still have limited information about how micro behavior generates patterns of aggregate commonpool exploitation. ${ }^{5}$ Empirical developments using micro data to study the commons ultimately have been hampered by the inability to observe repeated decisions of individual resource users and the methodological challenges of estimating dynamic games. 6

A return to Gordon's original application of the fishery provides a unique opportunity to estimate strategic interactions and quantify the inefficiencies of common-pool exploitation. The specific application in this paper is the North Carolina shrimp fishery for which we have daily fishing participation choices of a heterogeneous fleet of resource users over multiple years. We model these daily decisions in a finite-horizon dynamic game. For each fishing vessel, we specify a choice-specific value function, which consists of the current payoff plus the discounted payoff for future periods, and we recover structural profit parameters that can be used for ex ante and ex post policy evaluation.

The ability to measure efficiency losses from common-pool resource exploitation hinges

\footnotetext{
${ }^{2}$ If resource users are forward-looking rather than myopic as in the Gordon/Smith model, open access still leads to rent dissipation in the steady state but with a different dynamic adjustment path (Berck and Perloff 1984).

${ }^{3}$ Models that include growth and aging of biological resources reinforce the potential for timing effects (Clark 1990). Open access can lead to harvest before animals are reproductively mature or before they have reached a size that maximizes economic yield.

${ }^{4}$ A complementary literature applies game theory to common-pool fishery exploitation (Hannesson 1997; Levhari and Mirman 1980; Sumaila 1997). These studies focus on aggregate level modeling such that players are individual nations rather than fishing vessels.

${ }^{5} \mathrm{~A}$ large literature on capacity utilization in fisheries uses micro data to quantify the excess capacity in fisheries due to open access but without the dynamic component, e.g. Segerson and Squires (1993). See Kirkley, Paul and Squires (2002) for a review. Moreover, excess fishing capacity can be exacerbated when the fishery is regulated with season closures but still subject to open access (Homans and Wilen 1997).

${ }^{6}$ Many empirical studies examine whether Ostrom's criteria for successful common property resource management (Ostrom 1990) hold in particular cases, and small-N qualitative studies dominate this literature (Poteete and Ostrom 2008). While these studies are important for understanding how different institutions succeed or fail in excluding common-pool users, they do not provide empirical estimates of strategic interactions, nor do they quantify the potential efficiency gains from rationalization.
} 
not only on data availability but also on recent methodological developments in dynamic discrete choice modeling. For estimating the dynamic game, we use a two-stage estimator. In the first stage, we estimate the evolution of state variables that influence players' decisions. These factors are reflected in choice probabilities conditional on those state variables. In the second stage, since we have multiple continuous state variables, we use a simulation-based conditional choice probability estimator (Hotz et al. 1994; Bajari, Benkard and Levin 2007) to evaluate a choice-specific value function for each individual. Then we apply a pseudo maximum likelihood (PML) estimator (Aguirregabiria and Mira 2002, 2007) to recover the structural parameters. ${ }^{7}$

The central contribution of this paper is to provide an empirical estimate of inefficiency from common-pool resource exploitation based on a dynamic structural model with strategic interactions. We compare actual exploitation paths to optimal ones under a daily vessel allocation policy that accounts for individual heterogeneity, and measure the efficiency costs in terms of lost industry rents. We evaluate two different efficiency costs in the fishery: costs due to a stock externality and costs due to a congestion externality. The stock externality can be further decomposed into the traditional stock effects (more fishing reduces the stock and raises costs) and strategic interactions among players (fishermen go fishing earlier in the season because they anticipate lower stocks later due to the actions of others). These effects lead fishermen to exert more effort than is socially optimal. Surprisingly, the congestion externality is positive on average and increases the present value fishery profits. It reduces instantaneous profits, but dynamically it reduces effort and mediates the stock externality, producing a net long-run gain.

The rest of the paper is organized as follows. Section 2 presents the main model, followed by an illustration of the estimation strategy in section 3. A description of the shrimp fishery and data are in section 4 . Section 5 discusses the estimation results. Section 6 conducts counterfactual policy experiments. In the final section, we conclude and discuss future research.

\section{Model}

The shrimp fishery is an annual industry due to shrimp biology. Shrimp reproduce annually and have a maximum lifespan of roughly eighteen months. Juvenile shrimp migrate inshore in the spring, grow in estuaries during the summer and fall, and then swim back to the open ocean to spawn in the winter and spring. This behavior results in a major harvest season from early summer to early winter that concentrates in the estuaries and nearshore in the open ocean.

\footnotetext{
${ }^{7}$ Compared to NPL (nested pseudo-likelihood) estimator (Aguirregabiria and Mira 2002, 2007), PML does not iterate and stops with only two stages. We choose PML because NPL requires discretization of state variables and it evaluates value function on each discretized state point. Higher precision of the discretization implies higher computational costs. For our particular problem, we have many state variables, which limits the discretization precision. More importantly, we examine daily dynamic choices, requiring the state variable discretization to be on a very fine scale. For example, in the peak fishing time in 2000 , hundreds of vessels go fishing that day, but it only decreases the fish stock index (one of the state variables) by 0.06 , and the maximum stock index is 81 for that year. This implies that we require many points if we discretize the stock index. The precision requirement is so high that it simply prevents us from implementing NPL. Thus, we use simulation-based PML that allows for continuous state variables.
} 
Modeling an annual industry simplifies the stock externality problem. In fisheries, the stock externality can lead to two types of overfishing problems: 1) growth overfishing, which refers to harvesting a fish stock before it is economically mature (before the fish have grown large enough), and 2) recruitment overfishing, which refers to overharvesting adult fish that compromises the size of the fish stock in the following year. While it is important to differentiate these two stock externalities when choosing specific policy tools, most empirical bioeconomic studies are not able to do so. In our case, because shrimp are highly fecund and migrate offshore to spawn, the cross-year recruitment overfishing problem can be ignored, and we only need to consider growth overfishing within one year. This feature allows us to isolate the within-year stock growth externality and quantify the annual efficiency gains in the optimal scenario. Our empirical application resembles a repeated experiment in which each year of data is a replicate for examining the stock externality. Thus, we model individual daily fishing decisions in a finite-horizon framework in which one year is a complete decision period, letting $t$ denote the day of the year $t=1,2, \ldots T$, in which $T=365$.

Another key feature of the shrimp industry is that, if a fisherman exits the industry, the cost of re-entering is low. After investing in a fishing vessel, a fisherman can easily change the species target and enter a different fishery. Due to the low switching barrier, there is no clear boundary between entering and exiting the shrimp industry. For this reason, we make a reasonable assumption that there is a fixed and finite number of players (i.e., vessels) each year, indexed by $i=1, \ldots, N$, in which, $N$ is the maximum number of regular participants observed in all years in our sample.

The timing of the game is as follows: on each day of a year, each fisherman has an expectation of harvest and receives a random profit shock, and then all fishermen simultaneously decide whether to fish. After each fisherman makes his decision, he receives a flow utility from his action. The game is repeated each day throughout the year. Formally, each player faces the same binary action set $a_{i} \in\{0,1\}$, with 0 denoting not fishing and 1 denoting fishing. Let $A \equiv\{0,1\}^{N}$, which is a comprehensive list of possible actions for all players.

\section{A. Payoff}

In each period $t$, a fisherman $i$ receives the time-specific profit, $\Pi_{i t}$, which consists of a return to his individual characteristics and a random profit shock. His profit at time $t$, given his action, can be written as:

$$
\Pi_{i t}\left(a_{i}\right)= \begin{cases}\alpha \text { Price }_{t} * E\left(h_{i t}\right)-\beta * \mathbb{S}+\xi_{i t 1}, & \text { if } a_{i}=1 \\ \xi_{i t 0}, & \text { if } a_{i}=0\end{cases}
$$

In this equation, if $i$ does not go fishing, his profit is reserved to be zero plus some random shock; if $i$ goes fishing, his profit is equal to the revenue minus cost plus a random profit shock. The profit when going fishing is related to two random shocks, one is a profit shock $\xi_{i t 1}$, the other one is a harvest shock. The profit shock, $\xi_{i t}$, reflects random personal fishing costs (for example, illness, fatigue, or mood), idiosyncratic knowledge of that 
day's market or fishing conditions, or outside employment opportunities. It is different across choices and observed by fishermen before they make their fishing decisions. In addition, it is private information and observed only by themselves, and not by other fishermen and the researcher. This profit shock is assumed to be independently and identically distributed (i.i.d.) across fishermen and across periods, and drawn from an extreme value distribution. Another random shock is a harvest shock that appears in harvest $\left(h_{i t}\right)$. We assume that this random shock is not observed before fishermen go fishing. Thus, both revenue and cost are a function of expected harvest $\left(E\left(h_{i t}\right)\right)$, which has been integrated over the random harvest shock.

The revenue is the product of price (Price ${ }_{t}$ ) and expected harvest, and $\beta * \mathbb{S}$ is the cost of fishing, which is a function of state variables including the fish stock, fuel prices, weather, vessel length, and expected harvest:

$$
\beta * \mathbb{S}=g\left(\text { Len }_{i}, W S P D_{t}, W V H T_{t}, \text { Diesel }_{t}, \text { Weekend }_{t}, E\left(h_{i t}\right), X_{t}\right)
$$

Production costs include fixed, quasi-fixed, and variable costs. Fixed costs consist of capital investments in vessels, fishing gear, and safety and navigation equipment. The cost function here does not include fixed costs. When making the fishing or not fishing decisions, the fixed costs are sunk and irrelevant. Therefore, we cannot recover fixed costs through fishing behavior observed in our data. Quasi-fixed costs are costs that are incurred if a vessel chooses to fish on a given day, but are not related to the level of harvest. These include the depreciation value of vessel and gear, labor costs (assuming a fixed wage), food for the crew, and storage costs for the catch (ice or refrigeration, depending on the vessel). ${ }^{8}$ The number of workers required to operate a vessel increases in vessel length $\left(L e n_{i}\right)$, so we expect that the quasi-fixed costs of each trip are roughly proportional to the vessel length. Quasi-fixed costs also include the costs of exposure to bad weather (wind speed (WSPD) and wave height $(W V H T)$ ), fuel (diesel) price (Diesel), whether it is a weekend (Weekend), and fish stock index $(X)$. The cost from Weekend is due to government regulations (will be discussed later), and is also consistent with other studies of fisheries in which market conditions limit activity on weekends (Smith and Wilen 2005). Variable costs depend on the size of the harvest. Since fishermen only observe the harvest shock after they go fishing, we model the variable costs on the level of expected harvest. We expect that as harvest increases, the variable costs will increase. Note that the harvest level in the cost is also in the format of expected harvest as in the revenue.

Fishermen compete to produce shrimp by fishing, and harvest is a function of inputs. Fisheries economists usually measure fishing inputs by "effort", i.e. number of trip days, number of crew, amount of gear deployed, and vessel size etc. In addition, harvest is also determined by inputs outside the fisherman's direct control, including whether there is a season closure, wind speed, wave height, and the fish stock. Combining all these factors,

\footnotetext{
${ }^{8}$ Many fisheries use the share system to pay the crew, but the majority of shrimp fishing in North Carolina uses wage compensation.
} 
we use the following restricted Cobb-Douglas production function:

$$
\begin{aligned}
h_{i t} & =q_{i} * e^{a_{1} \text { Closure }_{t}+a_{2} W S P D_{t}+a_{3} W V H T_{t}} * X_{t} * e^{\varepsilon_{i t}^{h}} \\
& =q_{i} * e^{W_{t}} * X_{t} * e^{\varepsilon_{i t}^{h}}
\end{aligned}
$$

In the above equation, $q_{i}$ is individual catchability, which includes unobserved vessel fishing technology as well as captain skill and experience. ${ }^{9}$ After log-transforming Equation 3, fixed effects capture this unobserved individual heterogeneity. We assume that $q_{i}$ is common knowledge. Fish stock, $X_{t}$, is a major factor that determines catch. Stock is not observed by the researcher, although fishermen may have estimates of it based on their experiences and collectively on any given day face the same stock (Zhang and Smith 2011). Thus, in our production function, the stock is assumed to be observed by every vessel before they make decisions but treated as a latent state variable in our model. Besides the fish stock, the season closure policy and weather conditions also affect the catch. The total impact $a_{1}$ Closure $_{t}+a_{2} W S P D_{t}+a_{3} W V H T_{t}$ is denoted by $W_{t}$. The stochastic component, $e^{\varepsilon_{i t}^{h}}$, is the harvest shock we mentioned above in describing Equation 1. It is assumed to be i.i.d across individuals and time, and mean 1. The expectation of harvest in Equation 1 is integrated over this random shock. Note that there are no days at sea as a measure of fishing effort in this production function. This is because we convert multi-day trips to a series of one-day trips in order to simplify the model. ${ }^{10}$

We further allow for the possibility of agglomeration or congestion effects, which could affect revenue. Equation 3 accordingly includes an additional term:

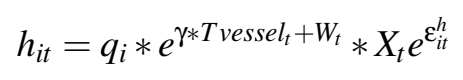

Here, the total number of vessels fishing $T$ vessel $_{t}=\sum\left(a_{i}=1\right)$ on day $t$ affects the catch through $\gamma$, which captures agglomeration or congestion effects. A positive (negative) $\gamma$ indicates agglomeration (congestion). Agglomeration in this context means that having more vessels increases the productivity of fishing, most likely by reducing the search costs. With congestion, more vessels reduce average harvests, likely because trawling disperses shrimp aggregations. ${ }^{11}$

With $e^{\varepsilon_{i t}^{h}}$ being stochastic with mean 1 , we can obtain the payoff function for vessel $i$

\footnotetext{
${ }^{9}$ This model is motivated by the Schaefer production function used commonly in fisheries bioeconomic modeling (Schaefer 1957). See Clark (1990) for further discussion. The argument fishing effort is omitted because implicitly effort is one in our model when fishing takes place and zero otherwise. Our model is more general than the Schaefer model in that it accounts for congestion, weather, regulations, and vessel-level fixed effects.

${ }^{10}$ The data show that 73.7 percent of trips are one day, and 25.9 percent of trips are between 2 to 6 days. To convert multi-day trips, we allocate the average daily harvest for the trip to each day.

11 The congestion effect enters multiplicatively such that it scales the catchability up or down, depending on whether there is congestion or agglomeration. An additive term would wrongly suggest that there could be positive (or negative) harvest in the absence of any other inputs. Other multiplicative functional forms are possible, but we have chosen one that is convenient for identification; it allows us to run linear instrumental variables.
} 
by replacing $E\left(h_{i t}\right)$ in Equation 1 when $a_{i}=1$.

$$
\Pi_{i t}=\alpha \text { Price }_{t} * q_{i} * e^{\gamma * T \text { vessel }_{t}+W_{t}} * X_{t}-\beta * \mathbb{S}+\xi_{i t}
$$

In this equation, all the state variables can be either observed or estimated.

\section{B. Transitions Between States}

Recall that the state variables include all individual characteristics and environmental information that affect a fisherman's utility. The variables Len $_{i}$ and Weekend ${ }_{t}$ are deterministic, while all others are stochastic. Wind speed and wave height are not influenced by fishermen's decisions and modeled as exogenous variables with Markov chains. The shrimp price is also assumed to be a stochastic exogenous variable because it is determined by the global market (North Carolina shrimp industry is only 0.6 percent of the world market ${ }^{12}$ ).

Formally, the shrimp price, wind speed, and wave height are modeled as follows:

$$
\begin{gathered}
\log \left(\text { Price }_{t+1}\right)=\rho_{0}+\rho_{1} \log \left(\text { Price }_{t}\right)+\varepsilon_{t}^{p} \\
\log \left(W S P D_{t+1}\right)=\rho_{2}+\rho_{3} \log \left(W S P D_{t}\right)+\varepsilon_{t}^{w} \\
\log \left(W V H T_{t+1}\right)=\rho_{4}+\rho_{5} \log \left(W V H T_{t}\right)+\varepsilon_{t}^{v} \\
\left(\begin{array}{c}
\varepsilon_{t}^{p} \\
\varepsilon_{t}^{w} \\
\varepsilon_{t}^{v}
\end{array}\right) \sim \text { i.i.d.Normal }\left[\left(\begin{array}{l}
0 \\
0 \\
0
\end{array}\right),\left(\begin{array}{lll}
\sigma_{p}^{2} & 0 & 0 \\
0 & \sigma_{w}^{2} & \sigma_{w, v} \\
0 & \sigma_{v, w} & \sigma_{v}^{2}
\end{array}\right)\right]
\end{gathered}
$$

The error term of shrimp price is assumed to be i.i.d. across time from normal distribution with mean 0 . Note that the correlations between wave speed and wave height are not zero because they are not independent of each other, while the correlations between wind speed or wave height and shrimp price are assumed to be zero. The diesel price, which is also stochastic but exogenous to the North Carolina shrimp fishery, is modeled with a flexible b-spline function (Chen 2007):

$$
\text { Diesel }_{t}=\rho_{6} * b s(\text { Week })+\varepsilon_{t}^{d},
$$

The variable "Week" is the week number within a year. The basis functions are bsplines to allow flexible fitting of the data, denoted as bs(.). The mean of error term, $E\left(\varepsilon_{t}^{d}\right)$, is equal to 0 .

The stock index is an endogenous latent state variable and is modeled as a discrete time stochastic difference equation (Reed 1974):

$$
X_{t}=X_{0} G(t) e^{-\phi \sum_{s=0}^{t} h(s)} e^{\zeta_{t}}
$$

\footnotetext{
${ }^{12}$ This number is calculated using information from State of World Fisheries and Aquaculture (SOFIA), 2006. Price appears to be exogenous even in the much larger Gulf of Mexico shrimp fishery (Asche et al. 2012).
} 
The term $X_{0}$ denotes initial stock at time 0 determined by nature (exogenous recruitment at the beginning of each year), $G$ denotes the deterministic portion of biological growth that is fixed across years, and $\sum_{s=0}^{t} h(s)$ is the cumulative harvest up to day $t$ within a year. $\phi$ is the fishing mortality coefficient to be estimated. Basically, the initial period's stock after harvest, multiplied by growth $(G(t))$, past fishing mortality within the same year $\left(e^{-\phi \sum_{s=0}^{t} h(s)}\right)$, and a random shock from nature $\left(e^{\zeta_{t}}\right)$, yields period t's stock. Since there is no good prior information to describe the multiple types of shrimp in the aggregate, we estimate natural growth $G(t)$ directly from our data. ${ }^{13}$. As in Reed (1974), we make the simplifying assumption that the stock population is not age-structured and can be described by a continuous variable. To capture seasonality of shrimp growth, we specify $G$ as a polynomial of time (days within each year), $e^{b_{1} \ln (t)+b_{2} \ln (t)^{2}+b_{3} \ln (t)^{3}+b_{4} \ln (t)^{4}}$. This seasonal component proxies for age structure of an annual species like shrimp as long as growth and aging are linked to calendar days consistently across years. The error term, $\zeta_{t}$, incorporates fluctuations in population growth and is known by fishermen before their fishing decisions are made. We discuss the stock index in more detail below in the section on estimation strategy.

\section{Choice-specific utility and expected utility}

To define the value function, it is useful to distinguish choice-specific utility from expected utility. Following common notation in the literature, let $a=\left(a_{1}, \ldots a_{N}\right)$ denote the vector of actions for all players and $a_{-i}=\left(a_{1}, \ldots a_{i-1}, a_{i+1}, \ldots, a_{N}\right)$ denote the vector of strategies of all players excluding player i. Define $s_{i} \in S_{i}$ as a vector of state variables $\left\{\right.$ Price $_{t}$, len $_{i}, X_{t}$, Weekend $_{t}, W S P D_{t}, W V H T_{t}$, Diesel $\left._{t}, q_{i}, t\right\}$, which are common knowledge to all the agents. Let $\theta$ denote the set of all the parameters in the utility function. Dropping t subscripts, the choice-specific utility is:

$$
u_{i}\left(a_{i}, a_{-i}, s, \xi_{i} ; \theta\right)= \begin{cases}\alpha \text { Price } * q_{i} * e^{\gamma * T \text { vessel }+W} * X-\beta * \mathbb{S}+\xi_{i 1}, & \text { if } a_{i}=1 \\ \xi_{i 0}, & \text { if } a_{i}=0\end{cases}
$$

The choice-specific utility is the payoff corresponding to different choices. Note that the utility value only depends on player i's private profit shocks and not on other agents' profit shocks. In the utility, "Tvessel" is not a state variable but affects choices instantaneously. Since it depends on other players' actions, it makes the current period utility not only dependent on his own action, but also dependent on other fishermen's actions. Therefore, we need to integrate out $a_{-i}$ to obtain the expected utility $u_{i}\left(a_{i}, s, \xi_{i} ; \theta\right)$. Define $\sigma_{i}\left(a_{i}=k \mid s\right)$ as the probability of player i choosing $\mathrm{k}$ conditional on known state

\footnotetext{
${ }^{13}$ Traditional ways of modeling growth use the Von-Bertalanffy growth function, which models changes in shrimp number and weight over time. Our stock index consists of three different types of shrimp (brown shrimp, white shrimp, and pink shrimp), and biologists only collect parameters in the Von-Bertalanffy growth function for the three types of shrimp separately from the field experiments. Our index can be viewed as an empirical approximation to the mixture of these growth functions (See different species profile at http://www.nbii.gov/portal/community/Communities/Plants,_Animals_\&_Other_Organisms/Fisheries_\&_Aquatic_ Resources/Aquatic_Organisms/Species_Profiles/)
} 
information, in which $k \in\{0,1\}$. Then the expected utility is:

$$
u_{i}\left(a_{i}, s, \xi_{i} ; \theta\right)=\sum_{a_{-i}} u_{i}\left(a_{i}, a_{-i}, s, \xi_{i} ; \theta\right) * \sigma_{-i}\left(a_{-i} \mid s\right)
$$

Note that since $u_{i}\left(a_{i}, a_{-i}, s, \xi_{i} ; \theta\right)$ is a function of $e^{\gamma * T \text { vessel }}$, integrating other players' actions in $u_{i}\left(a_{i}, a_{-i}, s, \xi_{i} ; \theta\right)$ with $e^{\gamma * T \text { vessel }}$ directly does not yield an analytical expression for $u_{i}\left(a_{i}, s, \xi_{i} ; \theta\right)$. In order to obtain an analytical solution, we approximate $e^{\gamma * T \text { vessel }}$ using a Taylor expansion.

$$
e^{\gamma * T \text { vessel }} \approx 1+\gamma * \text { Tvessel }+\frac{\gamma^{2}}{2} * \text { Tvessel }{ }^{2}
$$

Then $u_{i}\left(a_{i}=1, a_{-i}, s, \xi_{i} ; \theta\right)$ becomes:

$$
u_{i}\left(a_{i}=1, a_{-i}, s, \xi_{i} ; \theta\right)=\alpha \text { Price } * q_{i} *\left(1+\gamma * T \text { vessel }+\frac{\gamma^{2}}{2} * \text { Tvessel }^{2}\right) * e^{W} * X-\beta * \mathbb{S}+\xi_{i}
$$

in which

$$
\text { Tvessel }=\sum_{j} 1\left\{a_{j}=1\right\}
$$

Integrating out all the other fishermen's actions for Tvessel (See Supplemental Material for detailed information and Bajari et al. (2010) for a simple example), we obtain:

$$
\begin{aligned}
& u_{i}\left(a_{i}=1, s, \xi_{i} ; \theta\right)=\alpha \text { Price } * q_{i} * e^{W} * X \\
& *\left[1+\gamma+\frac{\gamma^{2}}{2}+\left(\gamma+\frac{3 \gamma^{2}}{2}\right) \sum_{j \neq i} \sigma_{j}\left(a_{j}=1 \mid s\right)+\frac{\gamma^{2}}{2} \sum_{j \neq k, j \neq i} \sum_{k \neq i} \sigma_{j}\left(a_{j}=1 \mid s\right) \sigma_{j}\left(a_{k}=1 \mid s\right)\right]
\end{aligned}
$$

$$
-\beta * \mathbb{S}+\xi_{i}
$$

\section{Equilibrium concept}

Given the primitives of the model above, we can write down the fisherman's optimization problem resulting in a Markov Perfect Equilibrium (MPE). Every period $t$ the agent chooses his action to maximize the expected utility

$$
\max _{\left\{a_{i t}\right\}} E_{t}\left[\sum_{j=t}^{T} \lambda^{j-1} u_{i j}\left(a_{i j}, s_{j}, \xi_{i j} ; \theta\right)\right]
$$

Here, $\lambda$ is the daily discount factor and $T$ is the maximum time of a year. In this maximization expression, all other players' actions and player $i$ 's own future actions have already been integrated away. If with details of other players' action, the objective 
function can be written as:

$$
V\left(s_{i t}, \xi_{i t}\right)=\max _{\left\{a_{i t}\right\}} E_{t}\left[\sum_{j=t}^{T} \lambda^{j-1} \sum_{a_{-i j}} u_{i j}\left(a_{i j}, a_{-i j}, s_{j}, \xi_{i j} ; \theta\right) * \sigma_{-i j}\left(a_{-i j} \mid s_{j}\right)\right]
$$

Players need to take consideration of current state variables, expectation of other players' current actions, their current private profit shocks, and expectation of future state variables, expectation of other players' future actions and their own future private shocks. Following notations in Aguirregabiria and Mira (2010), we define a set of strategy function for each agent as $\varphi_{i t}\left(s_{t}, \xi_{i t}\right)$ that depends on common state variables and his own private shock. Then, the probability that player $i$ chooses to fish at time $t$ is $\sigma_{i t}\left(a_{i t}=1 \mid s_{t}\right)=\int I\left(\varphi_{i t}\left(s_{t}, \xi_{i t}\right)=1\right) d F\left(\xi_{i t}\right)$. Let $V_{i t}^{\varphi}\left(a_{i t}, s_{t}, \xi_{i t}\right)$ denote the expected discounted present value when individual $i$ takes action $a_{i t}$, all other players behave according to strategies $\varphi_{-i}\left(s, \xi_{-i}\right)$ now and in the future, and player $i$ follows strategy $\varphi_{i}\left(s, \xi_{i}\right)$ in the future periods. Then, the best response function of each player given other players' strategies is:

$$
b_{i t}\left(s_{t}, \xi_{i t}, \varphi_{-i t}\right)=\arg \max _{\left\{a_{i t}\right\}}\left[V_{i t}^{\varphi}\left(a_{i t}, s_{t}, \xi_{i t}\right)\right]
$$

The resulting optimal fishing decision must maximize the choice-specific value function. The equilibrium is a set of strategy function $\varphi_{i t}^{*}\left(s_{t}, \xi_{i t}\right)$ that

$$
\varphi_{i t}^{*}\left(s_{t}, \xi_{i t}\right)=b_{i t}\left(s_{t}, \xi_{i t}, \varphi_{-i t}^{*}\right)
$$

which indicates that the resulting decision rules are consistent with the beliefs about behavior of other players, i.e. the decision rules and beliefs are the same in the equilibrium. This equilibrium concept imposes significant structure on the equilibrium noncooperative behavior of all players, and the empirical two-stage estimator we adopt is based on this condition.

\section{Estimation Strategy}

Since there are many agents and continuous state variables, we employ a conditional choice probability (CCP) two-stage estimator (Hotz and Miller 1993). This approach alleviates the curse of dimensionality that can arise in Nested Fixed Point Algorithm (NFXP) methods, which are typically used for single agent applications (Karlstrom, Palme and Svensson 2004; Rust 1987; Timmins 2003). ${ }^{14}$ The intuition for the CCP

\footnotetext{
${ }^{14}$ Since NFXP needs to solve the dynamic programming (DP) problem, the computational costs are often prohibitively high. In our model, several continuous state variables and hundreds of agents prevent solving the DP problem directly. Just solving the social planner's dynamic programming problem in our counterfactual experiment requires significant computational time, and that problem need only be solved once and has no strategic interactions. In NFXP models, the DP needs to be solved in every iteration of the econometric estimation. For a multiple-agent problem like our model, NFXP becomes computationally infeasible; the DP problem needs to be solved in every iteration for every agent. As a solution, Hotz and Miller propose the Conditional Choice Probability estimator, which does not require solving the dynamic programming problem even once. Subsequently in the literature, a number of computationally feasible estimators are proposed, e.g. recursive CCP, simulation-based CCP, two-step methods to improve or solve different problems. For
} 
estimator is that there is a one-to-one mapping between the conditional choice probability and the choice-specific value function under certain conditions (Hotz and Miller 1993). By inverting this mapping, the discounted part of the value function can be represented as a function of state transition probabilities and CCP's, which in turn can be estimated non-parametrically or approximated parametrically in a separate first stage.

We specifically apply a two-stage estimation procedure developed by Aguirregabiria and Mira $(2002,2007)$ based on simulated CCP (Hotz et al. 1994; Bajari, Benkard and Levin 2007). The first stage is to estimate parameters of the state equations that describe stock growth, shrimp price, weather variables, and diesel price, and then estimate conditional choice probabilities for fishing participation. In the the second stage, we simulate the dynamics of state variables and evaluate the expected utilities over different paths, and recover structural profit parameters by maximizing a Pseudo Log-Likelihood. ${ }^{15}$ Using this method, there is no need to solve the dynamic game in the estimation procedure.

The specification of the period utility function implies another important assumption of this model: observed and unobserved components of utility are additive, where the unobserved error is drawn from a known distribution (specifically, a Type I Extreme Value distribution), and is distributed i.i.d. across agents and time. Separability implies that the marginal utilities of observed state variables do not depend on unobservables (Aguirregabiria and Mira 2010). This assumption is imposed to facilitate identification of the second-stage parameters. If the additive separability assumption is violated, then additional computational problems will occur in maximum likelihood estimation (Rust 1994). The parametric known form of the error term is needed due to the fact that it is not possible to recover both parameters in observable components and the joint distribution of $\xi_{i}$ simultaneously (see Bajari et al. (2009)). Therefore, the known distribution is also a necessary identification assumption imposed on the error term.

\section{A. First-Stage Estimation}

The goal of the first stage is to estimate the state variable dynamics and choice probabilities flexibly without imposing the structure of the dynamic discrete choice model.

\section{ESTIMATION OF THE STATE VARIABLE DYNAMICS}

We use a Generalized Least Square (GLS) estimator to estimate the evolution of shrimp price and diesel price and a Seemingly Unrelated Regression (SUR) model for WSPD and WVHT. To estimate the stock index, we first linearize Equation 4 with Equation 11

\footnotetext{
instance, Slade (1998) applies this estimator to price adjustment in grocery stores and Aguirregabiria (1999) applies it to inventories and markups in retailing firms. Aguirregabiria and Mira (2010) review the estimators of dynamic discrete choice models.

${ }^{15}$ The efficiency of this two-stage estimator can be improved by iterations (Aguirregabiria and Mira 2002, 2007). Using the structural result of the second stage, the conditional choice probabilities can be updated and then used to reestimate the second stage, which completes the second iteration. However, as described above, the state space in our model is so large that it prevents us from implementing the recursive version described in (Aguirregabiria and Mira 2002, 2007).
} 
and use an Instrumental Variable (IV) regression model.

$$
\ln \left(h_{i t}\right)=\ln \left(X_{0}\right)+\ln \left(q_{i}\right)+\ln (G(t))-\phi \sum_{s=0}^{t} h(s)+\gamma * \text { Tvessel } t+W_{t}+\varepsilon_{i t}^{h}+\zeta_{t}
$$

Our estimation strategy for this equation is that we first estimate the regression model regarding $\varepsilon_{i t}^{h}+\zeta_{t}$ as one error term, and then regress the whole component on daily dummies to identify $\zeta_{t}$. The first regression estimation has two issues. First, Tvessel $t_{t}$ and $\zeta_{t}$ are not independent of each other due to the fact that the unobserved $\zeta_{t}$ could affect fishermen's decisions; a common positive (negative) stock shock for one vessel is likely correlated with that of other vessels and would attract more (fewer) vessels to the fishery on that day. In order to resolve the endogeneity problem, we use Weekend as an instrumental variable. Given that vessel $i$ is going fishing, Weekend is a valid instrument because it is correlated with fishing choices of everybody else but not correlated with a stock shock $\zeta_{t}$ from nature. Second, because we only observe output when vessels choose to fish, sample selection bias from unobserved shocks in the production function is possible. We may ameliorate this problem to a large extent by including the individual fixed effect $q_{i}$. ${ }^{16}$

In the IV regression, the regressors for $X_{0}$ are yearly dummy variables, and $G(t)$ are fixed across years from latent stock information but varies within a year. The term $\phi \sum_{s=0}^{t} h(s)$ proxies for cumulative fishing mortality throughout the season, $\ln \left(q_{i}\right)$ can be estimated using individual fixed effect. After obtaining $\varepsilon_{i t}^{h}+\zeta_{t}$, we identify $\zeta_{t}$ by regressing the whole error term on daily dummies across all years assuming that $\varepsilon_{i t}^{h}$ and $\zeta_{t}$ are independent with each other. The year*daily dummies are further approximated by a Markov chain to capture its dynamics. In the second stage of the structural estimation, $\zeta_{t}$ will be simulated according to the Markov chain. In theory, $\zeta_{t}$ reflects the random shock to fish stock. But since we do not observe stock and use daily fixed effect to identify it, it is possible that this daily fixed effect captures some individual-invariant but time-variant effect from harvest. If so, $\zeta_{t}$ is more general, but it is still endogeneous and does not affect other estimation and interpretation.

\section{CONDITIONAL CHOICE PROBABILITIES}

We estimate the fishing decision conditional on the state vector with a flexible logit model. In essence, we could use a nonparametric method to mimic the relationship between the state variables and the probabilities (Hotz and Miller 1993). But due to our large data set and long convergence rate of nonparametric methods, we use a logit model. As a way to replace the nonparametric method, we include all state variables (along with vessel fixed effects), squared terms, and the interactions among different

\footnotetext{
${ }^{16}$ In fact, our model assumes that vessel-specific harvest shocks $\varepsilon_{i t}^{h}$ are observed after fishing decisions are made, and the private payoff shocks $\xi_{i t}$ do not enter the harvest function and are independent of the harvest shocks. We also control for the random component of the fish stock $\zeta_{t}$. Under these assumptions, there should be no sample selection bias. Ellickson and Misra (2012) address a similar selection issue using post-choice outcome data. Although we lack postchoice outcomes for non-fishing alternatives and cannot apply this method here, their approach is potentially applicable to selection bias in multispecies fisheries.
} 
state variables to add flexibility. Ideally, we would include individual fixed effects, daily fixed effects, and interactions with states. However, to preserve degrees of freedom and rely on structural elements that can be used in a holdout sample, we interact individual fixed effects from the production function with state variables and include the daily stock shock as a regressor. Because individual and daily fixed effects cannot be known out-ofsample, including them in the first-stage CCP prevents out-of-sample model validation and thus limits the ability to conduct counterfactual policy experiments.

\section{B. Second-Stage Estimation}

As discussed above, this model is a finite horizon repeated game with an end period denoted as $T$. Let $u_{i t}\left(a_{i t}, s_{t} ; \theta\right)$ denote the expected choice specific utility without $\xi_{i t}$. We derive the recursive value function as

$V_{i t}\left(a_{i t}, s_{t} ; \theta\right)=u_{i t}\left(a_{i t}, s_{t} ; \theta\right)$

$$
+\sum_{\tau=t+1}^{T} \lambda^{\tau-t} \iint \sum_{a_{-i \tau}} u_{i \tau}\left(\varphi_{i \tau}^{*}\left(s_{\tau}, \xi_{i \tau}\right), a_{-i \tau}, s_{\tau}, \xi_{i \tau} ; \theta\right) * \sigma_{-i \tau}\left(a_{-i \tau} \mid s_{\tau}\right) d F\left(\xi_{i \tau}\right) d F\left(s_{\tau} \mid a_{\tau-1}, s_{\tau-1}\right)
$$

For the continuation part, we use simulations to approximate the recursive forward integration. Based on the observations of state variables and actions for each vessel at time $t$, we simulate the next period state variables according to the state transitions $F\left(s_{t+1} \mid a_{t}, s_{t}\right)$. Then we draw $\xi_{i(t+1)}$ for two potential actions from an i.i.d. Type I Extreme Value distribution. The decision rule, $\varphi^{*}\left(s_{t+1}, \xi_{i(t+1)}\right)$, can subsequently be applied to determine the action of each vessel. Given state variables and actions at $t+1$, state variables can be simulated for $t+2$, and the procedure repeats until it reaches time $T$. The state variables from time $t+1$ to $T$ are simulated a sufficient number of times to obtain the continuation part in Equation 22. The daily discount factor, $\lambda$, is set to 0.9998 in the estimation, which is equivalent to an annual discount rate of 7.04 percent. Because we assume the oneperiod utility function is additively separable for observable and unobservable variables (Equation 12), the future component in Equation 22 is also separable in the observed part and $\xi$. Equation 22 enables us to simulate different paths of the state dynamics and evaluate the associated choice-specific value functions for different vessels at different times. Since $\xi_{i t}$ is generated from a Type I Extreme Value distribution, the equilibrium conditions imply that:

$$
\sigma\left(a_{i}=1 \mid s\right)=\frac{\exp \left(V_{i}\left(a_{i}=1, s ; \theta\right)\right)}{1+\exp \left(V_{i}\left(a_{i}=1, s ; \theta\right)\right)}
$$

The above equation is a standard logit model except for the value function. We use the Pseudo-Likelihood Estimator (PML) to estimate $\theta$ (Aguirregabiria and Mira (2002, 
2007)). The log-likelihood function is:

$$
L(\theta)=\sum_{i=1}^{N} \sum_{t=1}^{T} \sum_{k=0}^{1} \ln \left(\sigma\left(a_{i t}=k \mid s\right)\right) * 1\left(a_{i t}=k\right)
$$

The entire model estimation is based on the assumption that fishermen's observed actions constitute a Markov Perfect Equilibrium. Given equations 23 and 24, the estimator for $\theta$ is.

$$
\widehat{\theta}=\arg \max _{\theta \in \Theta} L(\theta)
$$

The complete estimation procedure can be summarized in nine steps.

Step 1: Perform the first stage estimation, including exogenous state variable transitions, the fishing production function, stock dynamics, and conditional choice probabilities;

Step 2: Given state variables and actions at initial time $t=1$, draw new state variables and $\xi_{i}$ for each vessel $i$ for the next period;

Step 3: Decide actions according to the decision rule estimated in the first step.

Step 4: Continue steps 2 and 3 for each day $t=2,3, \ldots T$;

Step 5: Repeat step 2 to 4 a sufficient number of times and compute the average;

Step 6: Repeat steps 2 through 5 resetting the initial time on each loop $t=2,3, \ldots T$;

Step 7: Do steps 2 through 6 for each year in the sample;

Step 8: Compute Equation 22;

Step 9: Estimate $\theta$ using Equation 25.

The simulation-based Conditional Choice Probability and Pseudo Maximum Likelihood estimators save computational time. Because the period profit is a linear function of $\theta$ which have not already been estimated in the first stage, we can separate these parameters from the variables, and do not need to repeat step 2 to step 7 as many times as we iterate over $\theta$ to compute Equation 22. In other words, when we maximize log-likelihood function (Equation 24) to estimate $\theta$, we iterate over $\theta$ spaces to find the maximum without re-simulating the model.

\section{Empirical Setting and Data}

The empirical application is the North Carolina shrimp fishery. The economic value of the shrimp fishery has ranked first or second among all the fisheries in North Carolina over the last 30 years. The annual average landings between 1962 and 2003 are 7,011,236 lbs and the landings and shrimp abundance vary largely from year to year due to variation in environmental conditions (NCDENR-DMF 2006).

White shrimp (Penaeus setiferus), brown shrimp (Penaeus aztecus) and pink shrimp (Penaeus duorarum) are the three major shrimp species harvested commercially in North Carolina. They are landed predominantly from the Pamlico Sound, the Core Sound and the Atlantic Ocean. The life histories of these three species are similar except that the spawning times of the species vary. 
All three shrimp species have an annual life cycle that begins in the spring in deep offshore areas. After a few weeks of development, the postlarvae migrate inshore to estuarine nursery areas. These areas provide young shrimp with food and protection from predation. As shrimp mature, they start to move from the shallow nursery areas into deeper water. Adult shrimp continue to emigrate to offshore areas, leaving the estuary and preparing to spawn. Most adults spawn a single time, and then complete an annual life cycle. ${ }^{17}$

There are two main regulations in North Carolina that affect commercial shrimp fishing besides rules about net size and gear type. First, the shrimp season and fishing areas are specified each month to prevent overfishing. 18 For the Albemarle-Pamlico Estuary, where much of shrimp harvest occurs, the season usually closes in May and reopens in early June each year. Second, in order to protect recreational boating and fishing, shrimp trawling is banned in some of the inner estuaries on weekends (NCDENR-DMF 2006).

Three types of data are used in the analysis: harvest data, weather information, and diesel prices. Harvest data is the primary dataset and is collected by the North Carolina Division of Marine Fishery's (DMF) trip ticket program (2000-2005). The trip ticket is a required form on which dealers report commercial landings and other trip information. It records vessel length, number of crew, gear type, trip starting and landing dates, price, fishing location and quantity of each species landed for each trip. The dealers are required to submit the trip tickets to DMF every month. From 1978 to 1993, commercial landings information were collected on a voluntary basis. Since 1994, the N.C. General Assembly has mandated trip-level reporting, which has produced one of the most detailed state-level fisheries data collection programs in the United States.

In the trip ticket data, each vessel has a unique ID. The dataset contains over 2,000 unique IDs. However, not all the vessels are "active" ones. Shrimp may be caught as bycatch, i.e. caught incidentally on fishing trips that predominantly target other species. Or, shrimp can be caught by vessels that only go shrimping rarely. These vessels have very few landings but would significantly increase the computational burden if included in the model. Thus, we define an active vessel as one that has more than 100 records of landing shrimp over six years. This restriction leaves 439 individual vessels that constitute 85 percent of the total landings. Inactive vessels would likely have minor effects on the parameter estimation of our model.

Restricting the harvest data to only active vessels still leaves more than 63,000 observations of shrimp landings from 2000-2005. Figure 1 shows the total daily harvest over the 6 years and illustrates the annual seasonal pattern. Peak landing occur from July through October, which account for 80.83 percent of the annual harvest. This harvest distribution is consistent with a shrimp's annual life cycle. Shrimp harvest also varies substantially from year to year. Shrimp trawl dominates other gear types, accounting for 89.5 percent of total landings in sample.

[Figure 1 about here]

\footnotetext{
${ }^{17}$ Some shrimp can even survive as long as 18 months, but the annual life cycle is an accepted assumption in most shrimp biological modeling.

${ }^{18}$ For the detailed proclamation, see http://www.ncfisheries.net/procs/index $2 \mathrm{k} 8 . \mathrm{html}$
} 
Weather data, including wind speed and wave height, are compiled from the National Data Buoy Center (National Data Buoy Center 1994-2005). ${ }^{19}$ Since no buoy data directly represent the weather of the large Albemarle-Pamlico Estuary areas, we average weather data over three stations: Station DSLN7, Station CLKN7 and Station 44014. Vessels use \#2 marine diesel, but a detailed time series of its regional price is not available. As a substitute, we use weekly retail diesel price obtained from the Energy Information Administration (EIA) (U.S. Energy Information Administration 1994-2005). 20

By merging the landings data with weather and diesel price data, we construct a panel that includes daily decisions and harvest of 439 vessels in the Albemarle-Pamlico Estuary from 2000 to 2005, as well as vessel characteristics, daily weather, and weekly diesel price. Table 1 provides summary statistics for selected variables. The table shows that the total annual harvest varies over years, and daily catches have high volatility. Daily catch variation reflects variation in the shrimp stock dynamics as well as heterogeneous catching power and fishing skills of the different subsets of vessels participating on each day. The shrimp price is a weighted average obtained by dividing total value by total weight. Shrimp prices and diesel prices are adjusted for inflation using the Consumer Price Index. The mean shrimp price shows that real prices trend downward over these six years. Erosion of shrimp prices is generally attributed to increased competition from imports, including farm-raised shrimp from Asia (Asche et al. 2012). The diesel price also has a large variance, and not surprisingly, a clear increasing trend over 2000-2005. Incorporating the diesel prices into the cost structure allows for the examination of the effect of energy price changes on shrimp supplies. Note that we pool all years for estimating dynamics of shrimp prices and diesel prices.

[Table 1 about here]

\section{Empirical results}

\section{A. State transitions}

We first estimate the dynamics of the exogenous state variables. Before estimating time series models, we use Augmented Dickey-Fuller tests to see whether they are stationary processes. The output indicates that the natural log of shrimp price, wind speed, and wave height are stationary processes, and the natural log of diesel price is in need of differencing in order to render it stationary.

We fit autoregressive (AR) models to shrimp price, wind speed, and wave height series. The output is a vector AR(1) model. Wind speed and wave height may be highly correlated with each other, so we use a Seemingly Unrelated Regressions (SUR) model to recover their data generating processes simultaneously. The result shows that the model correlation between logged wind speed and logged wave height is 0.58 . For diesel price dynamics, we use cubic b-splines (degree equal to 3) with 30 knots of Week because

\footnotetext{
${ }^{19}$ The data source: http://www.ndbc.noaa.gov/maps/southeast_hist.shtml.

${ }^{20}$ The data source: http://tonto.eia.doe.gov/dnav/pet/pet_pri_gnd_a_epd2d_pte_cpgal_w.htm.
} 
diesel prices are collected on a weekly base. The b-spline allows for a flexible approximation for the diesel dynamics, which has a high adjusted R-square 0.98. Full results for the exogenous state variables, including tests for stationarity and b-spline estimation, are available in the Supplementary Material.

Parameter estimates of the production function and stock dynamics are presented in Table 2. The OLS column reports the result from regressing logged harvest on logged total vessel number (Tvessel), season closure, and dummies for year, vessel, and polynomials of $\ln (t)$. The columns labeled "IV" use "Weekend" as an instrument for total vessel number. Table 2 also contains the fishing mortality coefficient, which is negative as expected; more cumulative harvest reduces the stock relative to its deterministic withinseason baseline. We do not report the 439 vessel dummies due to space limitations. The coefficient for total vessel number is positive and significant in OLS, but negative and significant in the two-stage least square estimation. Thus using an instrument changes the results. ${ }^{21}$. According to the IV coefficient, one unit increase in vessel number will decrease each vessel's harvest in one day by 0.127 percent. This result reflects an instantaneous congestion externality. It is consistent with the tendency of shrimp trawling to disperse aggregations of shrimp.

[Table 2 about here]

Table 2 also reports instrument validity tests for IV strength. The partial $R^{2}$ and $\mathrm{F}$ tests suggest that "Weekend" is a relevant instrument because it explains significant variation in Tvessel in an auxiliary regression. We also recover the parameters of the withinseason stock dynamics in the production function, shown in Table 2. Figure 2 illustrates the deterministic stock index in year 2000. The bottom line depicts the stock index with harvest, while the top line plots the stock index without harvest. The stock is consistent with the harvest season. The IV regression error term is regressed on daily fixed effect to obtain $\zeta_{t}$. Furthermore, $\zeta_{t}$ is approximated by a Markov chain, which is shown in the Supplementary Material.

[Figure 2 about here]

\section{B. Policy function of fishing}

We use a flexible logit model to estimate the first-stage conditional choice probabilities (CCP) of the decision to fish. The results are presented in the Supplementary Material due to space limit. The full model contains polynomials of shrimp price, deterministic part of stock index, $\zeta_{t}$, diesel price, weekend, wind speed, wave height, season closure, individual catchability $q_{i}$, and interactions among different variables. This flexible structure is intended to capture as much information as possible to mimic the initial conditional choice probabilities.

\footnotetext{
${ }^{21}$ This sign reversal after instrumenting is consistent with findings in the recreational demand literature on congestion (Timmins and Murdock 2007).
} 


\section{Profit structure}

Given the state transitions and CCP estimated above, we are able to simulate the state variables and actions dynamically. After evaluating Equation 22, the pseudo maximum likelihood estimator is applied to derive the structural parameters.

The final estimates of the profit function reported in Table 3 comport with basic intuition. The third column shows the scale of different independent variables. If we calculate the marginal effect of different variables on the profit based on these parameters, we find that if harvest increases, both the total revenue and the cost increase. In fact, the profit is a concave function of the harvest since the coefficient for harvest squared is negative. Also, profit increases when the stock index increases. Higher Wind speed and wave height induce higher costs, which are expected. Interactions between vessel length and weather suggest that larger vessels have lower costs with high wind speed and wave height, a reasonable finding because larger vessels face lower risks in bad weather. In addition, the relationship between vessel length and cost is convex. Larger vessels face higher marginal costs that increase in vessel size.

[Table 3 about here]

\section{Model validation}

One natural concern about multiple stage estimation is the model performance. The second stage estimator depends on the accuracy of the first stage, i.e. CCP estimation. One way to resolve this issue is to iterate multiple times using NPL proposed by Aguirregabiria and Mira $(2002,2007)^{22}$. However, it is not computationally feasible to apply NPL directly to our problem. Thus, it is important to check the performance of our structural model.

To validate the model, we examine the explanatory power of the model predictions for the actual observations. When we simulate the system, we can predict fishermen's fishing choices and use Equation 21 to predict harvest. Then we regress the actual observations on the predicted values of total harvest and fishing vessel number using both the first-stage CCP estimator and the final structural estimator. Table 4 presents the results. The first row shows the result of regressing the observed daily total vessel number on the daily total vessel number predicted using the first-stage CCPs. Recall that in this stage, the CCPs are estimated using a logit model with flexible polynomial functions and interactions that do not lend themselves to a structural interpretation. The second row is the regression result for total daily harvest using the same logic. Between 57 percent to 83 percent of the observed variation can be explained by the predicted data. The third and fourth rows show R-squared from out-of-sample validation. Here, we estimate the state transitions using six years of data (2000-2005), but estimate the policy function of

\footnotetext{
${ }^{22}$ In fact, we tried a Pseudo-NPL method. Using second-stage PML results, we calculate the probabilities for all observed state variables. Then we regress the probability on a flexible function of state variables. Based on this function, we can repeat the first-stage simulation based CCP estimation again, which starts the second round. PML is again applied to obtain the new profit structure and then the new updated probability, and so on. Altogether we have done six iterations. Supplementary Material Table 6 reports the profit structure for second to sixth iterations. The method is similar in spirit to Sweeting (2013).
} 
fishing (CCP) based on five years of data (2000-2004), leaving year 2005 out. Then the total daily harvest and daily vessel numbers are predicted for all years using the new coefficients estimated from the partial data. We choose 2005 as our hold-out year because it is the most unusual year in our sample and thus likely to be the most difficult to predict; the shapes of daily total effort and harvest in 2005 do not fit as well as those in other years, but the R-squares are not very low. For other years, the prediction power is similar.

[Table 4 about here]

The fifth and sixth rows of Table 4 present results for regressing the actual observations on the predicted values using the full structural model with full data. R-squares show that 59 percent to 81 percent of the observed variation can be explained by the predicted data. The explanatory power is preserved compared to the first-stage CCP. By construction, the two-stage estimator imposes more structure and has fewer free parameters than the first-stage CCP. Figure 3 visually illustrates the validation of the model for the fifth row in the table.

[Figure 3 about here]

The final two rows of Table 4 present the results of using the two-stage structural model on 2000-2004 data to predict 2000-2005. The first stage is the same model estimation from row three and four, i.e. six years for state transitions estimation and five years for CCP estimation. The second-stage estimation relies on five years data, leaving 2005 out. Using the structural result, we then predict behavior in 2000-2005. Again, we see similar explanatory power compared to that using all of data. Compared to the full sample, the R-squared for 2005 actually improves slightly both for vessel number and harvest. Most importantly, the structural model outperforms the first-stage CCP out of sample despite CCP having much more flexibility to fit the data. This provides independent evidence that the structural model is useful for policy analysis. In all, the profit structure revealed in the two-stage estimator appears reasonable to implement the following counterfactual experiments. In the same table, we also report the weighted mean absolute percentage error (WMAPE) for different models. The WPAPE is defined as the absolute distance between predicted and actual data relative to actual data, which are then weighted by daily harvest. The result shows a similar pattern as the R-square.

\section{Counterfactual experiments}

With the profit structure of the North Carolina shrimp fishery recovered, we are able to compute the potential efficiency gains from rationalization. In the following, we first measure the economic gains if a daily vessel allocation policy is enforced to improve efficiency. We then evaluate the existing season closure policy. Finally, we calculate the efficiency change if there is no congestion effect.

\section{A. Efficiency gains under daily vessel allocation policy}

As individuals maximize their own profits taking other players' actions as given, the system achieves micro-level efficiency. By contrast, at the macro level the exploitation 
might not be efficient. Individuals pursuing their self interests will not lead to the social optimum when there are externalities. The social planner should maximize the total benefits to fishermen from the common-pool resource in terms of all individuals and all periods. To this end, the planner ideally can enforce a daily vessel allocation policy, in which the social planner decides which vessels are permitted to go fishing every day.

Consider the social planner's problem:

$$
V=\max _{\left\{I_{t}\right\}_{t=1}^{T}} E\left(\sum_{t=1}^{T} \lambda^{t-1} \Pi_{t}\right)
$$

S.t.

$$
\begin{aligned}
& \Pi_{t}=\sum_{i} E_{\xi_{i t}}\left(\left(\alpha \text { Price }_{t} * E\left(h_{i t}\right)-\beta * \mathbb{S}\right) * 1\left(a_{i}=1\right)+\xi_{i t}\right) \\
& X_{t}=X_{0} G(t) e^{-\phi \sum_{s=0}^{t} h(s)} e^{\zeta_{t}} \\
& E\left(h_{i t}\right)=q_{i} * e^{W_{t}} * X_{t} \\
& *\left[1+\gamma+\frac{\gamma^{2}}{2}+\left(\gamma+\frac{3 \gamma^{2}}{2}\right) \sum_{j \neq i} \sigma_{j}\left(a_{j}=1 \mid s\right)+\frac{\gamma^{2}}{2} \sum_{j \neq k, j . k \neq i} \sigma_{j}\left(a_{j}=1 \mid s\right) \sigma_{j}\left(a_{k}=1 \mid s\right)\right]
\end{aligned}
$$

Let $I_{t}$ define a 439 by 1 vector determining whether vessel $i$ is allowed to going fishing or not at time $t$. $I_{i t}$ is the $i^{t h}$ element of $I_{t}$. If the $i^{t h}$ element is equal to 1 , it means that vessel $i$ is going fishing, while 0 means vessel $i$ is not. The social planner seeks a path of vectors of allocated vessels $\left(I_{t}\right)$ to maximize the total profit for all vessels $\left(\Pi_{t}\right)$, given that he knows the stock dynamics and the profit structure.

In order to maximize the total profits, the social planner need to dispatch the most profitable vessels to fish every day. Since the profit structure (Table 3) has been revealed for each individual vessel, we can rank the vessels by their daily profitability and then choose the most profitable vessels to go fishing. Then we only need to find the daily fishing vessel numbers $\sum\left(I_{t}\right)$ for $t=1,2, \ldots 365$ for all six years in order to maximize the total benefits.

In summary, the social planner can use the following backwards induction procedure to find the optimal path for daily permitted vessel numbers.

Step 1: starting from the last day of the year $T$, for each discretized stock index, compute the corresponding daily expected profits and sort them by their expected profits;

Step 2: based on the ordered profits, derive a mapping matrix between each discretized stock size and the optimal number of permitted vessels $\sum\left(I_{t}\right)$;

Step 3: on the penultimate day $T-1$, compute the expected profit for each discretized value of the stock index. At this point, the profit is a summation of day $T-1$ and day $T$ expected profits. The day $T$ profit can be read from the existing mapping matrix for time $T$ from step 2 given known stock dynamics.

Step 4: derive a mapping matrix between each discretized stock size and the optimal number of permitted vessels for $T-1$ according to the comparison of the profits.

Step 5: repeat the procedure to derive the mapping matrices for all time periods.

With knowledge of the initial stock size (Table 2), the social planner can derive the optimal path of permitted vessel numbers $\sum\left(I_{t}\right)^{*}$ using these mapping matrices. Here, the precision of the stock discretization is set so that the fishermen's actions can affect 
stock index. For example, the maximum stock for year 2005 is 50 and we divide it into 2000 uniform units. With such high precision, the computation time is long. In order to substantially reduce the computational cost, we examine $\sum\left(I_{t}\right)$ for every five vessels and every twenty days over one year, i.e. the number is constrained as multiples of five and the same for every twenty days.

Figure 4 depicts optimal vessel numbers vs. the predicted vessel numbers using the method described above. The lines represent the optimal numbers of fishing vessels less predicted ones, which are derived from the simulation of the structural model. Averaging over thousands of stock paths, we obtain the predicted fishing vessel number. Correspondingly, the horizontal lines are simply zeros for points of reference. For almost all years, we find that the optimal numbers of fishing vessels are lower than the predicted ones in the early season. While in the season peak, the optimal numbers are greater than the predicted ones except in 2005. The pattern is more pronounced when a years stock size is larger. For 2005, since the stock is very low (in fact the lowest among six years), the industry is better off decreasing the number of vessels fishing throughout the year.

[Figure 4 about here]

We plot harvest and stock paths in Figure 5. The second and fourth column panels depict the stock path. The bottom lines are stock dynamics net of predicted harvest (harvest is based on actual behavior but excluding daily shocks to illustrate the seasonal patterns), the lines in the middle are the stocks with optimal harvests, while the top lines are the stocks without harvest. The stock grows larger in the optimal scenario compared to the actual. The other panels show the pattern of optimal less predicted harvest. As usual, the lines indicate the differences, and the horizontal lines are zeros for reference. In the early seasons, the optimal harvest should be lower than the predicted harvest. In the peak season, the harvest should be increased except 2005, since at this time, the stock is high and the marginal fishing cost is lower. Again, 2005 is special in that the harvest needs to be lowered to reduce fishing costs since the stock is the lowest.

[Figure 5 about here]

Figures 4 and 5 illustrate the sources of efficiency loss in our common-pool resource application. First, there are too many vessels fishing in the early seasons, an artifact of strategic interactions that trigger the race to fish. During these periods, the stock is not high and the productivity of fishing vessels is fairly low. Thus the fishing effort exerted in these periods is excessive and should be reduced. Second, the excess fishing effort in the early season causes lower stock in the peak season. This lower stock reduces the harvest on the one hand, and increases the fishing cost on the other hand. Third, the most profitable vessels are not necessarily the ones fishing. If we combine all the sources of efficiency loss together, we find that 1.90 million dollars per year are lost due to the inefficient exploitation scale and timing. This result and yearly efficiency losses are reported in Table 5. The table also reports the efficiency loss is 20 percent of the observed average annual revenue. We also estimate the status quo profit and find that the efficiency gain is about 49 percent of the rent without deducting the capital costs. If we included capital costs, this percentage would be substantially higher. Among the six 
years, 2002 has the highest efficiency loss in absolute value of $\$ 5.98$ million dollars and also has the highest percentage loss relative to the observed revenue.

[Table 5 about here]

Table 5 indicates that 2001, 2004 and 2005 have lower efficiency gains for absolute values. This is not surprising in light of the confluence of multiple exogenous factors eroding shrimp profitability in these years. From Table 1, we see that these years had relatively lower real shrimp price and lower trip harvest. Moreover, from Table 2, these years had much lower exogenous shrimp recruitment in the sample.

We also compute all the results for annual discount rates of 18 percent and 0 percent, which are reported in the Supplemental Material. We find that the results are similar in magnitude and very close in percentage terms because the discount rate assumptions also change the baseline rents. The total efficiency gains are $\$ 1.76$ million per year for 18 percent discount rate, and $\$ 2.01$ million for 0 percent.

\section{B. Program evaluation of the current season closure policy}

Using our structural model, we can also evaluate the existing season closure policy in North Carolina. It is important to recognize that the efficiency gains from a daily vessel allocation policy described above would be additional. The season closure policy closes some fishing areas from April to May, depending on the estimated abundance and growth of shrimp. To find results, we simulate the dynamic game using the structural model and setting the season closure coefficient to zero. Unlike the counterfactual experiments above, here we have no social planner. We find that if the current season closure policy is cancelled, the efficiency loss will be about $\$ 0.16$ million per year. The related findings are summarized in Table 5. We denote the efficiency gain due to the season closure policy as $E 3$. Among the six years, 2000 has the highest efficiency gain, which amounts to $\$ 0.55$ million. However, we find these efficiency gains (E3) are relatively small as compared to the efficiency gains from the vessel allocation policy $(E 1)$. On average, the current season closure policy only produces efficiency gains of 2 percent of the observed revenue $O R$. Another way to view this result is that the existing policy produces efficiency gains relative to open access that are just a small fraction of that what our counterfactual daily allocation policy would produce relative to the status quo.

The season closure policy could also be expanded. Only some fishing areas are closed, and we observe substantial harvest during this closure period. To fully understand the season closure policy, we can experiment with a strictly implemented policy that would shut the fishery down entirely during the closure period. Again, we do not use a social planner but assume no fishing during the closure period, simulate the resulting stock dynamics, and evaluate the resulting behavior that comes out of the structural model. The column denoted as $E 4$ in Table 5 reports the results of this experiment. The efficiency gains improve on the status quo but not by much. This result suggests that a more stringent season closure policy for the North Carolina shrimp fishery could constitute some small improvement on the existing second best policies. The current season closure policy already captures 75 percent of the efficiency loss if the policy would be fully implemented. Whether a strict season closure policy would be more politically feasible 
than the much more valuable daily vessel allocation policy is an open question.

\section{Congestion effects}

The efficiency gains under both the daily vessel allocation policy and the season closure policy consist of the gains from reducing players' strategic interactions and the impacts of the stock externality. Congestion is another externality involved in the harvest. In the process of estimating the stock index, we find a congestion effect in fishermen's harvest, indicated by the negative coefficient on Tvessel in the IV regression (Table 2). This effect is instantaneous in the production function. To measure the congestion effect dynamically, we set the coefficient for Tvessel to zero and re-simulate the system. Table 5 reports our finding of the gains of congestion effects. Counterintuitively, the congestion effect leads to a net gain of $\$ 0.48$ million per year, i.e., the congestion externality is positive on average. The reason is that congestion itself has two effects on profits. First, it reduces fishing revenues (and hence profits) instantaneously due to its negative sign. Second, fishermen reduce their fishing effort in response to this negative congestion effect, which increases the stock size dynamically. The higher stock reduces fishing costs and increases revenues later in the season. Thus, whether congestion is a net positive or negative externality is empirically determined by these two opposing effects.

In contrast to other years, 2001 shows a net loss from congestion. Figure 4 offers possible explanations. In other years, excess fishing effort worsens as the fishery approaches the peak (around day 200). In 2001, excess effort peaks much earlier, suggesting that the required reduction near its peak season is more modest and the largest instantaneous losses from congestion occur earlier in the season (and accordingly would be less discounted). The amount of reduction required to achieve the optimum, the timing of reduction, and its duration all suggest that there is less to gain by mitigating the stock effect in 2001 than in other years. The instantaneous losses from congestion thus outweigh the long-run gains. Nevertheless, on average we find that, in the North Carolina shrimp fishery, congestion has a positive effect on profits, which is about 5 percent of the mean annual revenues.

\section{Conclusion}

In this paper, we estimate a dynamic discrete choice model of a shrimp fishery and measure the costs of open access. The fishermen are modeled as playing a dynamic game in which each fisherman's action is influenced by other fishermen's actions through the stock externality. Because the shrimp fishery is an annual industry, we model the dynamic programming problem with a finite horizon. The two-stage simulation-based Conditional Choice Probability and pseudo maximum likelihood (PML) routines are employed to estimate the structural parameters. Our results have several important implications.

First and foremost, to promote the efficient use of the commons, policy instruments need to address the strategic and dynamic interactions of individuals. Our results strongly support the notion that the tragedy of the commons unfolds at the individual level and 
within each season. While this result alone may not be surprising in light of the voluminous theoretical literature on the commons as well as theoretical predictions specific to fisheries (Boyce 1992; Valcu and Weninger 2013), we are unaware of any previous empirical study demonstrating that individual strategic and dynamic behavior is the mechanism that drives inefficient use of the commons. In fisheries, the catch phrase to describe this strategic dynamic interaction is the race to fish, and the conventional wisdom amongst fisheries economists is that an individually transferable quota (ITQ) solves the commons problem. Under an ITQ, vessels are allocated a tradable share of a biologically sustainable cap each season, and the most efficient vessels fish by exploiting gains from trade. However, if the timing of exploitation within a season is an important source of inefficiency, it is unclear how an ITQ will solve the racing problem. Some fisheries undergoing rationalization have spontaneously formed cooperatives, e.g. the Alaskan crab fisheries. Whether it is possible for these cooperatives to dispatch effort as if they are following our theoretical daily vessel allocation policy is a question for future research. Anecdotally, it appears that there are de facto dispatchers in the recently rationalized New England groundfish fisheries. Here, the fisheries have organized into cooperatives called sectors in which a sector manager facilitates which vessels fish and which vessels stay in port (Scheld, Anderson and Uchida 2012).

In contrast to ITQs, our daily vessel allocation policy steers individuals toward a more efficient outcome on a finer time scale. As more fisheries around the world begin to rationalize, there will be many new empirical opportunities to analyze whether ITQs truly undo the race to fish and to explore more spatially and temporally refined policy instruments to address inefficiencies in common-pool resource use. The U.S. National Oceanic and Atmospheric Administration recently released its catch shares policy (NOAA 2010) promoting rights-based management of fisheries. The policy provides guidance to regional fishery management councils on how to design rationalization programs. However, the policy does not mention the within-season timing of exploitation as a design factor, and there are currently no ITQ fisheries that temporally delineate ITQs in this way. Will fine-scale externalities fix themselves under an annual ITQ? Given our empirical context, it is worth considering the experience of the Australian northern prawn fishery, which has an annual effort ITQ. In support of the notion that fine-scale problems fix themselves, 96 percent of right-holders have formed a corporation that makes daily management decisions. But weighing against this notion, shutting down the fishery even for short periods is still considered politically infeasible (Dichmont et al. 2010).

A related point is the efficiency gains from rationalizing North Carolina's shrimp fishery, though sizable, may actually be smaller than one would find in a typical fishery. When rationalized by a daily allocation system, the total efficiency gain is around $\$ 1.90$ million per year, which is 20 percent of the annual shrimp revenue in North Carolina. However, shrimp are atypical compared to most major commercial fisheries in that there is a weak stock-recruitment relationship; that is, what returns next season has little to do with how much is left this season because shrimp are highly fecund and recruitment depends largely on environmental conditions. This feature of shrimp biology obviates the need for a cap on total allowable catch and is the basis for economists promoting 
limited entry to manage shrimp (Johnson and Libecap 1982). Most fisheries, in contrast, present the possibility of both recruitment overfishing (across seasons) and growth overfishing (within season). Rationalizing a typical fishery may thus generate larger efficiency gains by imposing a cap on total harvest for the season and by controlling the timing of exploitation within the season.

Less intuitively, we find that congestion on average has a net positive effect on resource rents, suggesting a cautionary tale about static models of congestion. As expected, the instantaneous effect is negative because congestion lowers productivity. This finding is sensible in our case, as shrimp trawlers require a wide berth, there are many shallow areas of the Abermarle-Pamlico estuarine system that limit the areas in which trawling is possible, and trawling is known to disperse aggregations of shrimp. However, the resulting lower productivity leads to an instantaneous reduction in fishing effort and thus mitigates some of the dynamic stock externality in all but one year. This finding questions studies in recreation demand in which negative congestion externalities are examined statically and thus are assumed to be welfare reducing. A positive net effect may or may not arise in other natural resource settings. It may be important to consider the possibility that welfare losses attributed to congestion actually would produce welfare gains dynamically if policy makers were unable to exclude resource users effectively.

Despite substantial gains from our daily allocation policy, solving the commons problem does not guarantee resource industry profitability. In 2005, the total rents with the optimal policy are still lower than the total status quo rents in any other year in the sample. This weak performance is due to low shrimp prices, high fuel costs, and low shrimp recruitment. These factors respectively reflect global seafood markets, global oil markets, and local environmental conditions, all of which are beyond the control of fishery managers and individual fishermen. Ameliorating strategic interactions in the commons does not address these challenges. Nevertheless, failure to solve commons problems means that the industry is ill positioned to withstand a bad year in which multiple exogenous shocks compound.

An interesting extension of this present study would be to include entry and exit as endogenous decisions. Since in the present data, there is no information to identify whether a vessel is a new investment or has exited the industry permanently, we assume there is a fixed number of vessels every year. But if the investment or sale of the vessels is modeled, we might be able to explain whether overcapitalization persists in the fishery. Since the potential exitors have paid a high entry fixed cost and sunk cost, there exists "hysteresis" in exiting (Dixit 1989). In other words, the entry-exit problem is asymmetric: it is easy to enter but harder to exit. With some extensions of the current work, it is possible to test whether the asymmetric entry-exit problem causes overcapitalization.

Lastly, our application illustrates how new methodological developments in industrial organization and microeconometrics may find fishery data sets useful. There are notable complications relative to other applications in industrial organization, such as the importance of the fish stock, the inability to observe the stock directly, and the nonlinearity of its growth. And one naturally wants to exercise caution in generalizing from a single industry with some idiosyncratic features. Nevertheless, fisheries can be sources of 
high-quality data that document repeated choices of individual players over time. The heterogeneity of global seafood production also means that the number of players in a fishery can range widely from less than ten to more than 1,000 . These extensions, along with other interesting applications about the dynamics of the common-pool resource exploitation, are left for future research. 


\section{REFERENCES}

Aguirregabiria, Victor. 1999. "The Dynamics of Markups and Inventories in Retailing Firms." The Review of Economic Studies, 66(2): 275-308.

Aguirregabiria, Victor, and Pedro Mira. 2002. "Swapping the Nested Fixed-Point Algorithm: a Class of Estimators for Discrete Markov Decision Models." Econometrica, 70: 1519-1543.

Aguirregabiria, Victor, and Pedro Mira. 2007. "Sequential Estimation of Dynamic Discrete Games." Econometrica, 75(1): 1-53.

Aguirregabiria, Victor, and Pedro Mira. 2010. "Dynamic Discrete Choice Structural Models: A Survey.” Journal of Econometrics, 156(1): 38-67.

Asche, F., L.S. Bennear, A. Oglend, and M.D. Smith. 2012. "U.S. Shrimp Market Integration." Marine Resource Economics, 27: 181-192.

Bajari, Patrick, C. Lanier Benkard, and Jonathan Levin. 2007. "Estimating Dynamic Models of Imperfect Competition.” Econometrica, 75(5): 1331-1370.

Bajari, Patrick, Han Hong, John Krainer, and Denis Nekipelov. 2010. "Estimating Static Models of Strategic Interaction." Journal of Business and Economics Statistics, 28(4): 469-482.

Bajari, Patrick, Victor Chernozhukov, Han Hong, and Denis Nekipelov. 2009. "Semiparametric Estimation of a Dynamic Game of Incomplete Information." Unpublished.

Baland, Jean-Marie, and Jean-Philippe Platteau. 2003. "Economics of Common Property Management Regimes." In Handbook of Environmental Economics. Vol. 1, , ed. Karl-Göran Mäler and Jeffrey Robert Vincent, Chapter 4, 127-190. Elsevier NorthHolland, Amsterdam.

Berck, Peter, and Jeffrey M Perloff. 1984. "An Open-Access Fishery with Rational Expectations.” Econometrica, 52(2): 489-506.

Bjørndal, Trond, and Jon M. Conrad. 1987. "The Dynamics of an Open Access Fishery." Canadian Journal of Economics, 20(1): 74-85.

Boyce, J.R. 1992. "Individual Transferable Qutoas and Production Externalities in a Fishery." Natural Resource Modeling, 6: 385-08.

Brander, James A., and M. Scott Taylor. 1998. "The Simple Economics of Easter Island: A Ricardo-Malthus Model of Renewable Resource Use.” The American Economic Review, 88(1): 119-139.

Chen, Xiaohong. 2007. "Large Sample Size Estimation of Semi-Nonparametric Models." In Handbook of Econometrics. Vol. 6B, Chapter 76. Elsevier. 
Clark, Colin W. 1990. Mathematical Bioeconomics: The Optimal Management of Renewable Resources. Wiley-Interscience.

Dasgupta, Partha, and Geoffrey M. Heal. 1979. Economic Theory and Exhaustible Resources. Cambridge University Press.

Dawes, Robyn M. 1973. "The Commons Dilemma Game: An N-person Mixed-motive Game with a Dominating Strategy for Defection.” Oregon Research Institute Research Bulletin, 13: 1-12.

Dichmont, C.M., S. Pascoe, T. Kompas, A.E. Punt, and R. Deng. 2010. "On Implementing Maximum Economic Yield in Commercial Fisheries." Proceedings of the National Academy of Sciences, 107(1): 16-21.

Dixit, Avinash K. 1989. "Entry and Exit Decisions under Uncertainty.” Journal of Political Economy, 97(3): 620-38.

Ellickson, Paul B., and Sanjog Misra. 2012. "Enriching Interactions: Incorporating Outcome Data into Static Discrete Games." Quantitative Marketing and Economics, 10(1): 1-26.

Gordon, H. Scott. 1954. "The Economic Theory of a Common-Property Resource: The Fishery." Journal of Political Economy, 62(2): 124-142.

Hannesson, Rognvaldur. 1997. "Fishing as a Supergame." Journal of Environmental Economics and Management, 32(3): 309-322.

Hardin, Garrett. 1968. "The Tragedy of the Commons." Science, 162(3859): 12431248.

Homans, Frances R., and James E. Wilen. 1997. "A Model of Regulated Open Access Resource Use.” Journal of Environmental Economics and Management, 32(1): 1-21.

Hotz, Joseph V., and Robert A. Miller. 1993. "Conditional Choice Probabilities and the Estimation of Dynamic Models.” The Review of Economic Studies, 60(3): 497-529.

Hotz, Joseph V., Robert A. Miller, Seth Sanders, and Jeffrey Smith. 1994. "A Simulation Estimator for Dynamic Models of Discrete Choice." The Review of Economic Studies, 61: 265-289.

Johnson, Ronald N., and Gary D. Libecap. 1982. "Contracting Problems and Regulation: The Case of the Fishery." The American Economic Review, 72(5): 1005-22.

Karlstrom, Anders, Marten Palme, and Ingemar Svensson. 2004. "A dynamic programming approach to model the retirement behaviour of blue-collar workers in Sweden." Journal of Applied Econometrics, 19(6): 795-807.

Kirkley, James, Catherine J. Morrison Paul, and Dale Squires. 2002. "Capacity and Capacity Utilization in Common-pool Resource Industries." Environmental and Resource Economics, 22(1-2): 71-97. 
Levhari, David, and Leonard J. Mirman. 1980. "The Great Fish War: An Example Using a Dynamic Cournot-Nash Solution.” Bell Journal of Economics, 11(1): 322334.

Libecap, Gary D., and Steven N. Wiggins. 1984. "Contractual Responses to the Common Pool: Prorationing of Crude Oil Production." The American Economic Review, 74(1): 87-98.

Linde-Rahr, Martin. 2003. "Property Rights and Deforestation: The Choice of Fuelwood Source in Rural Viet Nam." Land Economics, 79(2): 217-234.

Mendelsohn, Robert O. 1994. "Property Rights and Tropical Deforestation." Oxford Economic Papers, 46(0): 750-56.

National Data Buoy Center. 1994-2005. "Southeast USA Historical Marine Data." http://www.ndbc.noaa.gov/maps/southeast_hist.shtml (accessed February 9, 2009).

NCDENR-DMF. 2006. “North Carolina Fishery Management Plan: Shrimp.” Division of Marine Fisheries Report.

NOAA. 2010. "NOAA Catch Share Policy.” National Oceanic and Atmospheric Administration Report.

Ostrom, Elinor. 1990. Governing the Commons. Governing the Commons: The Evolution of Institutions for Collective Action.

Poteete, Amy R., and Elinor Ostrom. 2008. "Fifteen Years of Empirical Research on Collective Action in Natural Resource Management: Struggling to Build Large-N Databases Based on Qualitative Research.” World Development, 36(1): 176-195.

Provencher, Bill, and Oscar Burt. 1993. "The Externalities Associated with the Common Property Exploitation of Groundwater." Journal of Environmental Economics and Management, 24(2): 139-158.

Reed, William J. 1974. "A Stochastic Model for the Economic Management of a Renewable Animal Resource." Mathematical Biosciences, 22: 313-337.

Rust, John. 1987. “Optimal Replacement of GMC Bus Engines: An Empirical Model of Harold Zurcher." Econometrica, 55(5): 999-1033.

Rust, John. 1994. "Estimation of Dynamic Structural Models, Problems and Prospects: Discrete Decision Processes." In Proceedings of the 6th World Congress of the Econometric Society, Barcelona, Spain., ed. Christopher A. Sims and Jean-Jacques Laffont. Cambridge: Cambridge University Press.

Schaefer, M.B. 1957. "Some Considerations of Population Dynamics and Economics in Relation to the Management of Marine Fishes." Journal of the Fisheries Research Board of Canada, 14: 669-81. 
Scheld, Andrew M., Christopher M. Anderson, and Hirotsugu Uchida. 2012. "The Economic Effects of Catch Share Management: The Rhode Island Fluke Sector Pilot Program.” Marine Resource Economics, 27(3): 203-228.

Segerson, Kathleen, and Dale Squires. 1993. "Capacity Utilization under Regulatory Constraints." The Review of Economics and Statistics, 75(1): 76-85.

Sethi, Rajiv, and E. Somanathan. 1996. "The Evolution of Social Norms in Common Property Resource Use." The American Economic Review, 86(4): 766-788.

Slade, Margaret E. 1998. "Optimal Pricing with Costly Adjustment: Evidence from Retail-Grocery Prices.” The Review of Economic Studies, 65(1): 87-107.

Smith, Martin D., and James E. Wilen. 2005. "Heterogeneous and Correlated Risk Preferences in Commercial Fishermen." Journal of Risk and Uncertainty, 31: 53-71.

Smith, Vernon L. 1969. “On Models of Commercial Fishing.” Journal of Political Economy, 77(2): 181.

Smith, Vernon L. 1975. "The Primitive Hunter Culture, Pleistocene Extinction, and the Rise of Agriculture." Journal of Political Economy, 83(4): 727-55.

Sumaila, Ussif Rashid. 1997. "Strategic Dynamic Interaction: The Case of Barents Sea Fisheries." Marine Resource Economics, 12(2).

Sweeting, Andrew. 2013. "Dynamic Product Positioning in Differentiated Product Markets: The Effect of Fees for Musical Performance Rights on the Commercial Radio Industry." Econometrica, 81(5): 1763-1803.

Timmins, Christopher. 2003. "Measuring the Dynamic Efficiency Costs of Regulators' Preferences: Municipal Water Utilities in the Arid West." Econometrica, 70(2): 603629.

Timmins, Christopher, and Jennifer Murdock. 2007. "A Revealed Preference Approach to the Measurement of Congestion in Travel Cost Models." Journal of Environmental Economics and Management, 53(2): 230-249.

U.S. Energy Information Administration. 1994-2005. "Weekly Retail Diesel Prices." http://tonto.eia.doe.gov/dnav/pet/pet_pri_gnd_a_epd2d_pte_cpgal_w. htm (accessed March 16, 2009).

Valcu, Adriana, and Quinn Weninger. 2013. "Markov-Perfect Rent Dissipation in Rights-Based Fisheries.” Marine Resource Economics, 28(2).

Wilen, James E. 1976. "Common Property Resources and the Dynamics of Overexploitation: The Case of the North Pacific Fur Seal." University of British Columbia, Resources Paper, 3.

Zhang, Junjie, and Martin D. Smith. 2011. "Estimation of a Generalized Fishery Model: a Two-stage Approach." Review of Economics and Statistics, 93: 690-99. 

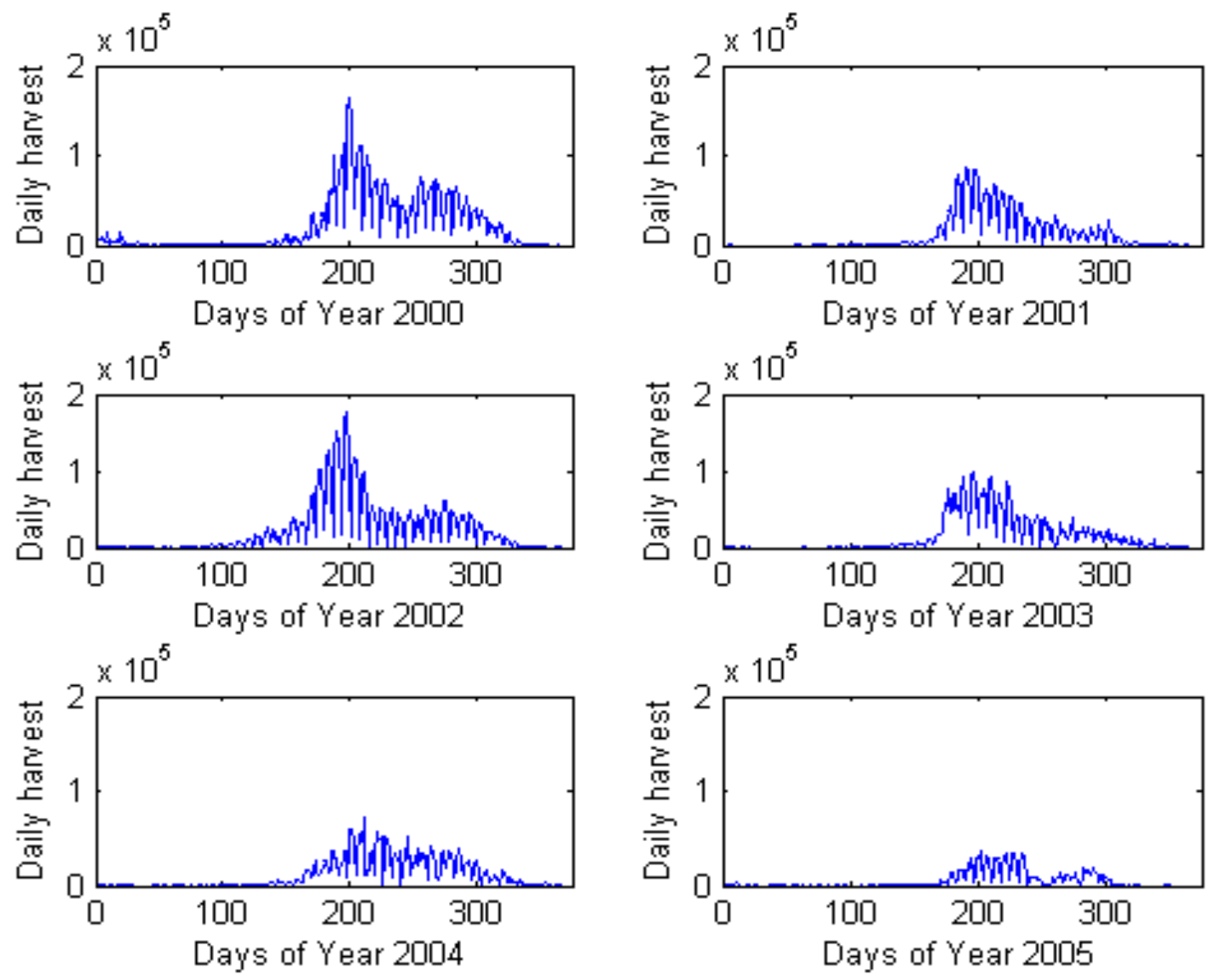

Figure 1. TOTAL DAILY HARVEST (POUNDS) 


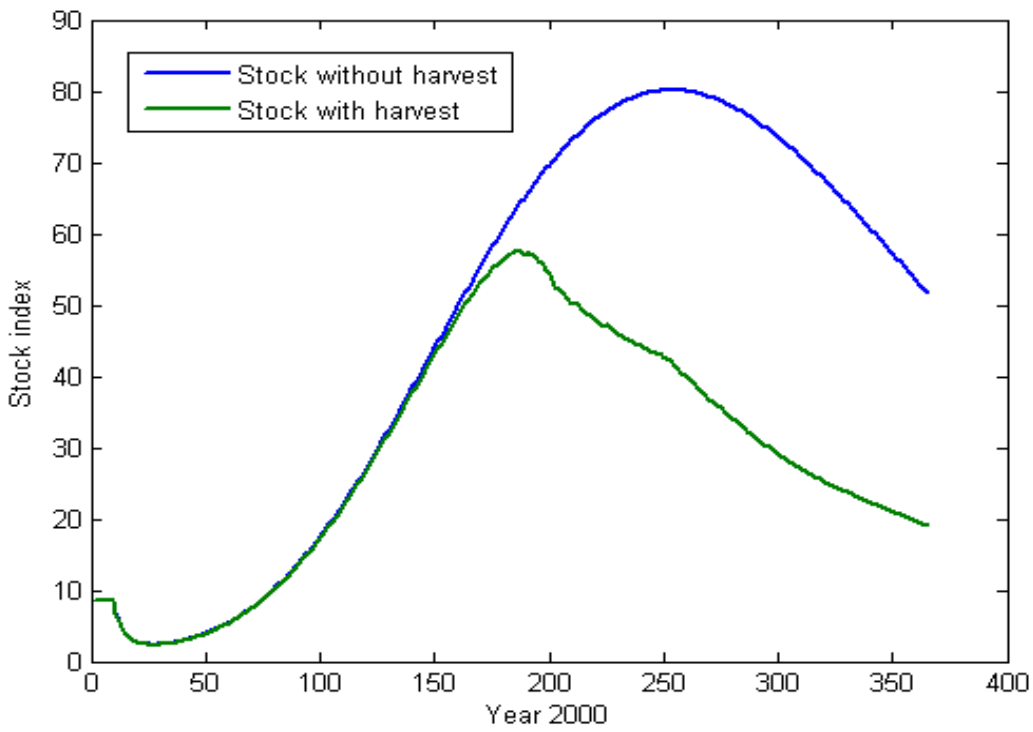

FIGURE 2. DETERMINISTIC PART OF THE DAILY STOCK INDEX OVER ONE YEAR 

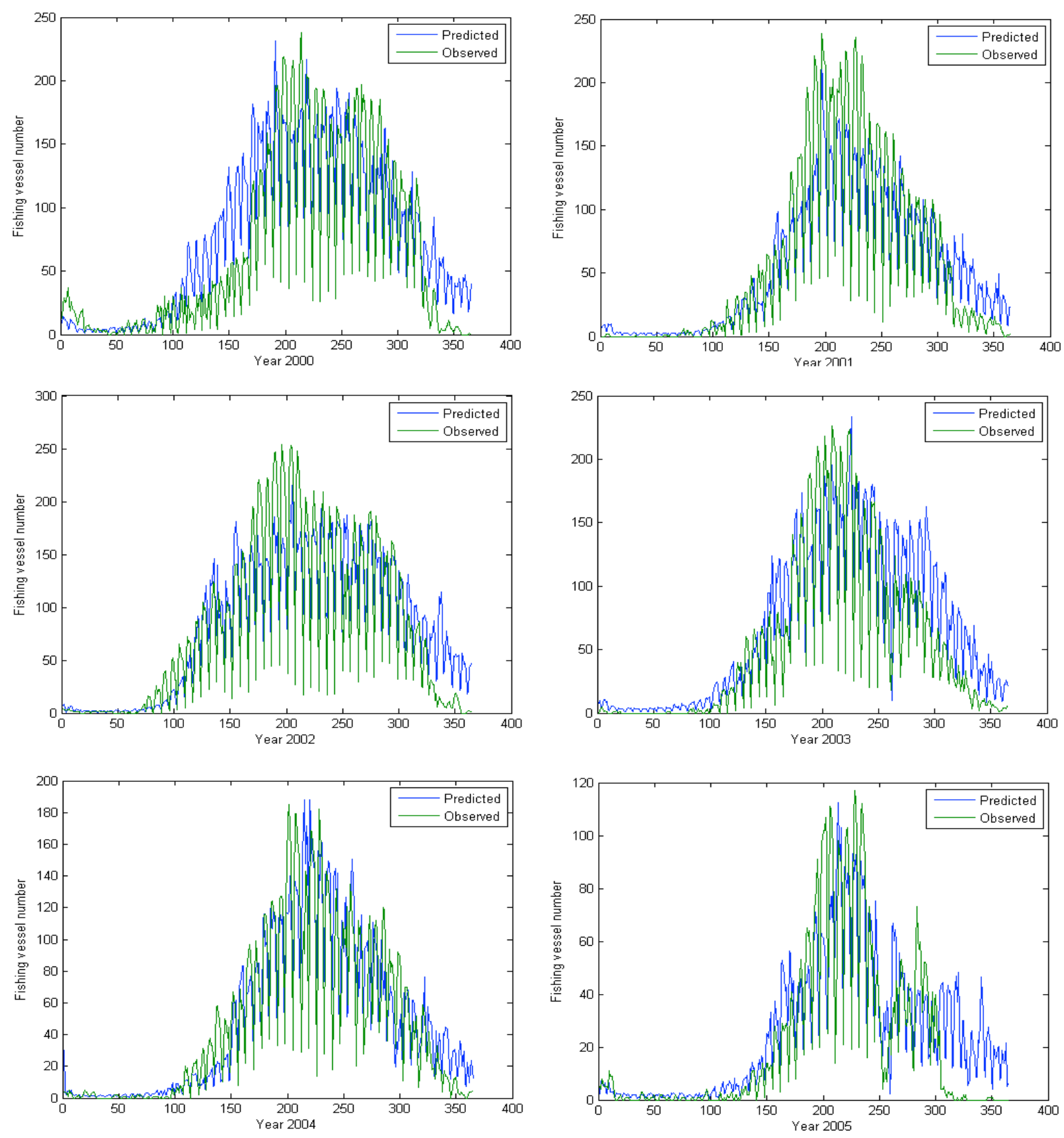

FIGURE 3. COMPARISON OF PREDICTED FISHING VESSEL NUMBER AND OBSERVED FISHING VESSEL NUMBER 

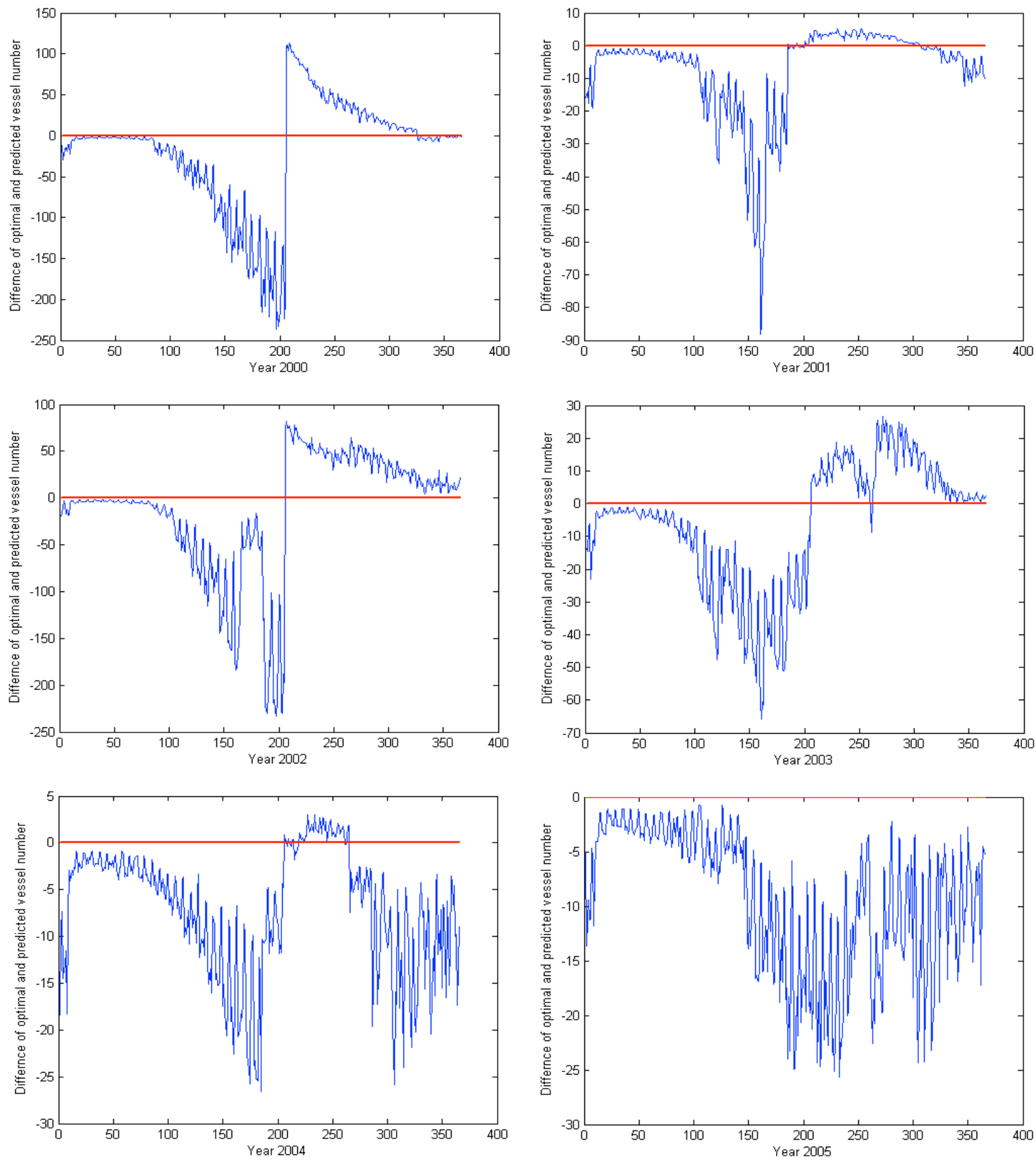

FIGURE 4. DIFFERENCES BETWEEN OPTIMAL FISHING VESSEL NUMBER AND PREDICTED FISHING VESSEL NUMBER UNDER THE MPE 

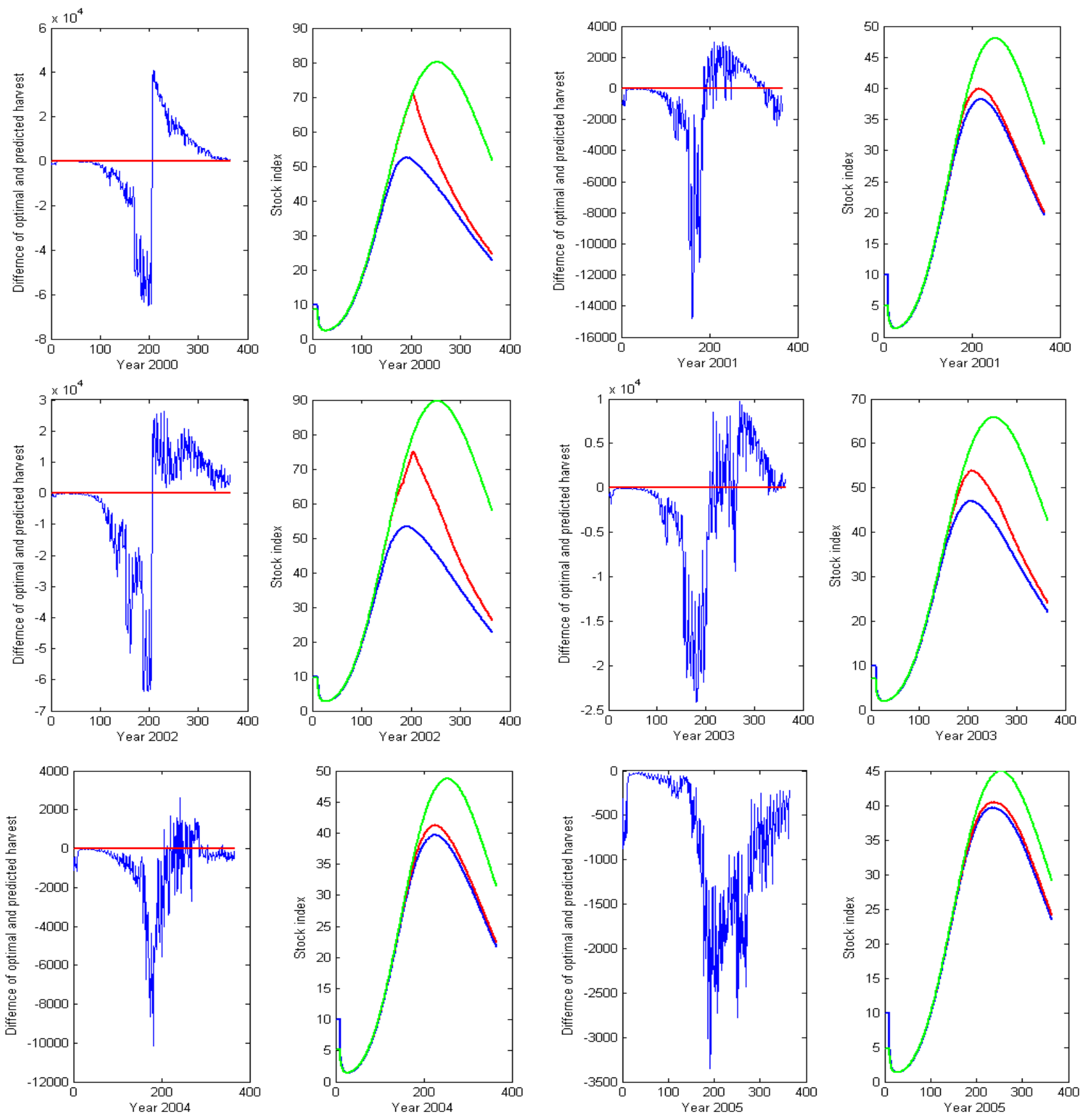

FIGURE 5. DAILY PREDICTED HARVEST AND STOCK COMPARED TO DAILY OPTIMAL HARVEST AND STOCK

Note: For reference, the top stock line is the stock with no fishing and stock here refers to the deterministic part of stock index. 
Table 1 -Summary Statistics for Selected State Variables

\begin{tabular}{|c|c|c|c|c|c|c|c|}
\hline Variable & Statistics & 2000 & $\overline{2001}$ & 2002 & $\overline{2003}$ & 2004 & 2005 \\
\hline $\begin{array}{l}\text { Annual harvest } \\
\text { (thousand pounds) }\end{array}$ & Sum & 10334.9 & 5254.2 & 9969.0 & 6167.4 & 4880.8 & 2123.5 \\
\hline \multirow{4}{*}{$\begin{array}{l}\text { Daily total } \\
\text { harvest } \\
\text { (thousand } \\
\text { pounds) }\end{array}$} & Mean & 28.3 & 14.4 & 27.3 & 16.9 & 13.4 & 5.8 \\
\hline & Std. Dev. & 31.2 & 20.1 & 33.9 & 23.1 & 15.2 & 8.7 \\
\hline & Minimum & 0 & 0 & 0 & 0 & 0 & 0 \\
\hline & Maximum & 163.0 & 87.0 & 175.2 & 99.0 & 71.1 & 36.3 \\
\hline \multirow{4}{*}{$\begin{array}{l}\text { Trip harvest } \\
\text { (Pound) }\end{array}$} & Mean & 313.6 & 199.9 & 272.4 & 251.1 & 220.5 & 207.0 \\
\hline & Std. Dev. & 473.8 & 255.3 & 333.3 & 371.4 & 309.3 & 228.0 \\
\hline & Minimum & 0.3 & 1.0 & 0.9 & 1.0 & 0.2 & 0.5 \\
\hline & Maximum & 16326.1 & 7067.0 & 10012.6 & 10281.5 & 6941.2 & 4051.9 \\
\hline \multirow{4}{*}{$\begin{array}{l}\text { Fishing vesel } \\
\text { number }\end{array}$} & Mean & 71.5 & 63.0 & 88.2 & 61.7 & 52.9 & 25.2 \\
\hline & Std. Dev. & 75.5 & 76.5 & 87.1 & 75.6 & 58.4 & 37.0 \\
\hline & Minimum & 0 & 0 & 0 & 0 & 0 & 0 \\
\hline & Maximum & 277 & 273 & 303 & 292 & 230 & 145 \\
\hline \multirow{4}{*}{$\begin{array}{l}\text { Shrimp price } \\
\text { (\$/pound) }\end{array}$} & Mean & 2.4 & 2.2 & 2.0 & 1.9 & 1.9 & 1.8 \\
\hline & Std. Dev. & 0.6 & 0.5 & 1.6 & 0.9 & 0.9 & 0.7 \\
\hline & Minimum & 1.0 & 1.0 & 0.6 & 0.9 & 0.7 & 0.7 \\
\hline & Maximum & 7.1 & 6.4 & 16.1 & 15.7 & 15.1 & 7.1 \\
\hline \multirow{4}{*}{$\begin{array}{l}\text { Diesel price } \\
\text { (cents/gallon) }\end{array}$} & Mean & 150.3 & 135.8 & 126.1 & 144.0 & 164.0 & 212.9 \\
\hline & Std. Dev. & 9.8 & 10.4 & 8.4 & 10.3 & 18.9 & 27.3 \\
\hline & Minimum & 130.2 & 114.0 & 111.7 & 134.4 & 137.8 & 176.7 \\
\hline & Maximum & 166.7 & 154.2 & 143.6 & 170.9 & 200.7 & 282.6 \\
\hline \multirow{4}{*}{$\begin{array}{l}\text { Wind speed } \\
(100 \mathrm{~m} / \mathrm{s})\end{array}$} & Mean & 7.3 & 6.7 & 7.0 & 6.4 & 6.1 & 7.1 \\
\hline & Std. Dev. & 2.7 & 2.6 & 2.3 & 2.5 & 2.7 & 2.9 \\
\hline & Minimum & 2.0 & 2.1 & 2.5 & 1.8 & 1.8 & 1.2 \\
\hline & Maximum & 17.0 & 14.5 & 14.2 & 19.3 & 14.9 & 21.6 \\
\hline \multirow{4}{*}{$\begin{array}{l}\text { Wave height } \\
\text { (m) }\end{array}$} & Mean & 1.2 & 1.3 & 1.4 & 1.5 & 1.4 & 1.5 \\
\hline & Std. Dev. & 0.5 & 0.5 & 0.5 & 0.7 & 0.7 & 0.8 \\
\hline & Minimum & 0.3 & 0.1 & 0.5 & 0.1 & 0.4 & 0.5 \\
\hline & Maximum & 3.0 & 3.2 & 5.3 & 8.5 & 5.3 & 5.8 \\
\hline
\end{tabular}


VOL. VOL NO. ISSUE THE DYNAMIC EFFICIENCY COSTS OF COMMON-POOL RESOURCE EXPLOITATION 37

TABLE 2-PRODUCTION REgRESSION

\begin{tabular}{|c|c|c|c|c|}
\hline \multicolumn{5}{|c|}{ "Panel A: Production Function* } \\
\hline & \multicolumn{2}{|c|}{ OLS } & \multicolumn{2}{|c|}{ IV } \\
\hline Parameter & Coefficient & Standard Error & Coefficient & Standard Error \\
\hline Tvessel & 0.00291 & $(0.000)$ & -0.00127 & $(0.000)$ \\
\hline Season closure( 1 if open) & 0.491 & $(0.015)$ & 0.717 & $(0.018)$ \\
\hline Wind Speed & 0.0004 & $(0.002)$ & -0.004 & $(0.002)$ \\
\hline Wave Height & 0.040 & $(0.007)$ & 0.022 & $(0.007)$ \\
\hline vessel dummies & Yes & Yes & Yes & Yes \\
\hline \multicolumn{5}{|c|}{ Panel B: Stock Dynamics** } \\
\hline year2000 & 0.375 & $(0.022)$ & 0.577 & $(0.023)$ \\
\hline year2001 & -0.188 & $(0.015)$ & 0.067 & $(0.018)$ \\
\hline year2002 & 0.446 & $(0.021)$ & 0.690 & $(0.023)$ \\
\hline year2003 & 0.189 & $(0.016)$ & 0.381 & $(0.017)$ \\
\hline year2004 & -0.044 & $(0.013)$ & 0.080 & $(0.014)$ \\
\hline year2005 & - & - & - & - \\
\hline $\ln (\mathrm{t})$ & 5.050 & $(0.271)$ & 9.855 & $(0.323)$ \\
\hline $\ln (t)^{2}$ & -3.818 & $(0.152)$ & -7.395 & $(0.205)$ \\
\hline $\ln (\mathrm{t})^{3}$ & 0.906 & $(0.033)$ & 1.797 & $(0.048)$ \\
\hline $\ln (t)^{4}$ & -0.066 & $(0.002)$ & -0.137 & $(0.004)$ \\
\hline Harvest_accumulated & -0.000000177 & $(0.000)$ & -0.000000127 & $(0.000)$ \\
\hline Observations & \multicolumn{2}{|c|}{80,802} & \multicolumn{2}{|c|}{80,802} \\
\hline \multicolumn{5}{|c|}{ Panel C: Tests for instrument validity } \\
\hline & $\begin{array}{c}\text { Partial R2 } \\
0.1752\end{array}$ & $\begin{array}{c}\mathrm{F}(1,80349) \\
17065.66\end{array}$ & $\begin{array}{c}\text { P-value } \\
0.0000\end{array}$ & \\
\hline
\end{tabular}

*Note: The columns labeled with "IV" use "Weekend" as an instrument for Total vessel number. 
TABLE 3-Profit Structure

\begin{tabular}{lllcc}
\hline \hline Parameter & Description & Scale & Coefficient & (Standard Error) \\
\hline revenue & Shrimp price*Harvest & 1000 dollars & 1.43 & $(0.021)$ \\
wspd & Wind speed & $1 \mathrm{~m} / \mathrm{s}$ & -0.13 & $(0.003)$ \\
wvht & Wave height & 1 meter & -0.29 & $(0.015)$ \\
diesel & Diesel price & 1 dollars & -0.02 & $(0.000)$ \\
Weekend & Saturday or Sunday & 1 1 stock index unit & -0.84 & $(0.008)$ \\
stock & stock size & 0.06 & $(0.000)$ \\
len & Vessel length & 10 feet & -0.31 & $(0.009)$ \\
len & Vessel length squared & 100 & -0.04 & $(0.001)$ \\
len_wspd & Length*Wind speed & 100 & 0.13 & $(0.006)$ \\
len_wvht & Length*Wave height & 100 & 0.33 & $(0.029)$ \\
len_diesel & Length*diesel & 100 & 0.02 & $(0.000)$ \\
har & Harvest & 1000 pounds & -1.61 & $(0.109)$ \\
har_len & Harvest*length & 10,000 & 0.67 & $(0.021)$ \\
har & Harvest squared & $1 \mathrm{E}+6$ & -5.16 & $(0.086)$ \\
\hline
\end{tabular}

Note: All harvest in this table is expected harvest. 
TABLE 4-MOdeL VALIDATION

\begin{tabular}{|c|c|c|c|c|c|c|}
\hline \multicolumn{7}{|c|}{ Panel A: R-square of regressing actual data on simulated data } \\
\hline year & 2000 & 2001 & 2002 & 2003 & 2004 & 2005 \\
\hline \multicolumn{7}{|c|}{ Model estimation using all data CCP only } \\
\hline Total vessel number & 0.75 & 0.83 & 0.72 & 0.75 & 0.79 & 0.73 \\
\hline Total daily harvest & 0.68 & 0.61 & 0.57 & 0.62 & 0.69 & 0.65 \\
\hline \multicolumn{7}{|c|}{ Model estimation using data 2000-2004 CCP only } \\
\hline Total vessel number & 0.70 & 0.82 & 0.80 & 0.80 & 0.81 & 0.41 \\
\hline Total daily harvest & 0.65 & 0.66 & 0.62 & 0.67 & 0.72 & 0.53 \\
\hline \multicolumn{7}{|c|}{ Model estimation using all data-structural model } \\
\hline Total vessel number & 0.69 & 0.74 & 0.81 & 0.81 & 0.80 & 0.63 \\
\hline Total daily harvest & 0.70 & 0.59 & 0.70 & 0.72 & 0.72 & 0.65 \\
\hline \multicolumn{7}{|c|}{ Model estimation using data 2000-2004-structural model } \\
\hline Total vessel number & 0.69 & 0.77 & 0.81 & 0.83 & 0.81 & 0.66 \\
\hline Total daily harvest & 0.70 & 0.60 & 0.70 & 0.73 & 0.73 & 0.66 \\
\hline \multicolumn{7}{|c|}{ Panel B: Weighted Mean Absolute Percentage Error } \\
\hline year & 2000 & 2001 & 2002 & 2003 & 2004 & 2005 \\
\hline \multicolumn{7}{|c|}{ Model estimation using all data CCP only } \\
\hline Total vessel number & 0.33 & 0.34 & 0.33 & 0.42 & 0.31 & 0.36 \\
\hline Total daily harvest & 0.48 & 0.53 & 0.49 & 0.56 & 0.45 & 0.57 \\
\hline \multicolumn{7}{|c|}{ Model estimation using data 2000-2004 CCP only } \\
\hline Total vessel number & 0.46 & 0.29 & 0.28 & 0.47 & 0.38 & 2.35 \\
\hline Total daily harvest & 0.50 & 0.53 & 0.47 & 0.50 & 0.38 & 1.37 \\
\hline \multicolumn{7}{|c|}{ Model estimation using all data-structural model } \\
\hline Total vessel number & 0.35 & 0.43 & 0.26 & 0.36 & 0.39 & 0.45 \\
\hline Total daily harvest & 0.49 & 0.59 & 0.46 & 0.49 & 0.47 & 0.67 \\
\hline \multicolumn{7}{|c|}{ Model estimation using data 2000-2004-structural model } \\
\hline Total vessel number & 0.36 & 0.42 & 0.25 & 0.35 & 0.35 & 0.40 \\
\hline Total daily harvest & 0.49 & 0.58 & 0.45 & 0.48 & 0.44 & 0.69 \\
\hline
\end{tabular}


